\title{
Separating Electrophilicity and Lewis Acidity: The Synthesis, Characterization, and Electrochemistry of the Electron Deficient Tris(aryl)boranes $\mathrm{B}\left(\mathrm{C}_{6} \mathrm{~F}_{5}\right)_{3-n}\left(\mathrm{C}_{6} \mathrm{Cl}_{5}\right)_{n}(n=1-3)$
}

\author{
Andrew E. Ashley, ${ }^{*+,+}$ Thomas J. Herrington, ${ }^{\dagger}$ Gregory G. Wildgoose, ${ }^{\S}$ Hasna Zaher, ${ }^{\dagger}$ Amber L. Thompson, ${ }^{\dagger}$ \\ Nicholas H. Rees, ${ }^{\dagger}$ Tobias Krämer, ${ }^{\dagger}$ and Dermot O’Hare ${ }^{*}$ \\ ${ }^{+}$Chemistry Research Laboratory, Department of Chemistry, University of Oxford, Mansfield Road, Oxford, OX1 3TA, United Kingdom \\ ${ }^{\S}$ School of Chemistry, University of East Anglia, Norwich, NR4 7TJ, United Kingdom
}

S Supporting Information

ABSTRACT: A new family of electron-deficient tris(aryl)boranes, $\mathrm{B}\left(\mathrm{C}_{6} \mathrm{~F}_{5}\right)_{3-n}\left(\mathrm{C}_{6} \mathrm{Cl}_{5}\right)_{n}(n=1-3)$, has been synthesized, permitting an investigation into the steric and electronic effects resulting from the gradual replacement of $\mathrm{C}_{6} \mathrm{~F}_{5}$ with $\mathrm{C}_{6} \mathrm{Cl}_{5}$ ligands. $\mathrm{B}\left(\mathrm{C}_{6} \mathrm{~F}_{5}\right)_{2}\left(\mathrm{C}_{6} \mathrm{Cl}_{5}\right)(3)$ is accessed via $\mathrm{C}_{6} \mathrm{Cl}_{5} \mathrm{BBr}_{2}$, itself prepared from donor-free $\mathrm{Zn}\left(\mathrm{C}_{6} \mathrm{Cl}_{5}\right)_{2}$ and $\mathrm{BBr}_{3}$. Reaction of $\mathrm{C}_{6} \mathrm{Cl}_{5} \mathrm{Li}$ with $\mathrm{BCl}_{3}$ in a $\mathrm{Et}_{2} \mathrm{O} /$ hexane slurry selectively produced $\mathrm{B}\left(\mathrm{C}_{6} \mathrm{Cl}_{5}\right)_{2} \mathrm{Cl}$, which undergoes $\mathrm{B}-\mathrm{Cl}$ exchange with $\mathrm{CuC} \mathrm{F}_{5}$ to afford $\mathrm{B}\left(\mathrm{C}_{6} \mathrm{~F}_{5}\right)\left(\mathrm{C}_{6} \mathrm{Cl}_{5}\right)_{2}(5)$. While 3 forms a complex with $\mathrm{H}_{2} \mathrm{O}$, which can be rapidly removed under vacuum or in the presence of molecular sieves, $\mathrm{B}\left(\mathrm{C}_{6} \mathrm{Cl}_{5}\right)_{3}(6)$ is completely stable to refluxing toluene $/ \mathrm{H}_{2} \mathrm{O}$ for several days. Compounds 3,5 , and $\mathbf{6}$ have been structurally characterized using single crystal $\mathrm{X}$-ray diffraction and represent the first structure determinations for compounds featuring $\mathrm{B}-\mathrm{C}_{6} \mathrm{Cl}_{5}$ bonds; each exhibits a trigonal planar geometry about $\mathrm{B}$, despite having different ligand sets. The spectroscopic characterization using ${ }^{11} \mathrm{~B},{ }^{19} \mathrm{~F}$, and ${ }^{13} \mathrm{C}$ NMR indicates that the boron center becomes more electron-deficient as $n$ increases. Optimized structures of $\mathrm{B}\left(\mathrm{C}_{6} \mathrm{~F}_{5}\right)_{3-n}\left(\mathrm{C}_{6} \mathrm{Cl}_{5}\right)_{n}(n=0-3)$ using density functional theory (B3LYP/TZVP) are all fully consistent with the experimental structural data. Computed ${ }^{11} \mathrm{~B}$ shielding constants also replicate the experimental trend almost quantitatively, and the computed natural charges on the boron center increase in the order $n=0(0.81)<n=1(0.89)<n=2(1.02)<n=3(1.16)$, supporting the hypothesis that electrophilicity increases concomitantly with substitution of $\mathrm{C}_{6} \mathrm{~F}_{5}$ for $\mathrm{C}_{6} \mathrm{Cl}_{5}$. The direct solution cyclic voltammetry of $\mathrm{B}\left(\mathrm{C}_{6} \mathrm{~F}_{5}\right)_{3}$ has been obtained for the first time and electrochemical measurements upon the entire series $\mathrm{B}\left(\mathrm{C}_{6} \mathrm{~F}_{5}\right)_{3-n}\left(\mathrm{C}_{6} \mathrm{Cl}_{5}\right)_{n}(n=0-3)$ corroborate the spectroscopic data, revealing $\mathrm{C}_{6} \mathrm{Cl}_{5}$ to be a more electron-withdrawing group than $\mathrm{C}_{6} \mathrm{~F}_{5}$, with a ca. $+200 \mathrm{mV}$ shift observed in the reduction potential per $\mathrm{C}_{6} \mathrm{~F}_{5}$ group replaced. Conversely, use of the GuttmannBeckett and Childs' methods to determine Lewis acidity on $\mathrm{B}\left(\mathrm{C}_{6} \mathrm{~F}_{5}\right)_{3}, 3$, and $\mathbf{5}$ showed this property to diminish with increasing $\mathrm{C}_{6} \mathrm{Cl}_{5}$ content, which is attributed to the steric effects of the bulky $\mathrm{C}_{6} \mathrm{Cl}_{5}$ substituents. This conflict is ascribed to the minimal structural reorganization in the radical anions upon reduction during cyclic voltammetric experiments. Reduction of 6 using $\mathrm{Na}_{(\mathrm{s})}$ in THF results in a vivid blue paramagnetic solution of $\mathrm{Na}^{+}[6]^{\bullet-}$; the EPR signal of $\mathrm{Na}^{+}[6]^{\bullet-}$ is centered at $g=2.002$ with $a\left({ }^{11} \mathrm{~B}\right)$ 10G. Measurements of the exponential decay of the EPR signal $(298 \mathrm{~K})$ reveal $[6]^{0^{-}}$to be considerably more stable than its perfluoro analogue.

\section{INTRODUCTION}

In 1963, Massey and co-workers reported the synthesis of tris(pentafluorophenyl)borane, noting its tendency to form a variety of strongly bound adducts with phosphines, ammonia and ethers. ${ }^{1} \mathrm{~B}\left(\mathrm{C}_{6} \mathrm{~F}_{5}\right)_{3}$ has since found numerous applications in both organic chemistry (e.g. silylation of alcohols, hydrosilylation of ketones and imines, reductive cleavage of alcohols and ethers $)^{2}$ and inorganic chemistry (e.g. synthesis of weakly coordinating anions, anion-binding, activator in transition metal-mediated $\alpha$ olefin polymerizations). ${ }^{3}$ These attributes are related to its powerful Lewis acidity, which has been measured to be intermediate between $\mathrm{BF}_{3}$ and $\mathrm{BCl}_{3}$. ${ }^{4}$ However, unlike these gaseous species, it is a thermally robust solid (due to its strong $\mathrm{B}-\mathrm{C}$ and $\mathrm{C}-\mathrm{F}$ bonds) and is water-tolerant, lending itself to ease of handling. ${ }^{5}$ Indeed, $\mathrm{B}\left(\mathrm{C}_{6} \mathrm{~F}_{5}\right)_{3}$ has been described as the "ideal boron-based Lewis acid, due to its high acid strength and stability, even at elevated temperatures, combined with a substantial steric bulk". $5 \mathrm{~b}$ A more recent role for this molecule is as a Lewis acid partner in Frustrated Lewis Pair (or FLP) chemistry ${ }^{6}$ wherein steric preclusion from adduct formation with a Lewis base leads to unusual reactivity such as $\mathrm{H}_{2}$ heterolysis and small molecule activation with alkenes/alkynes, ${ }^{7} \mathrm{CO}_{2}{ }^{8}$ and $\mathrm{N}_{2} \mathrm{O}$. ${ }^{9}$ The enhanced reactivity of $\mathrm{H}_{2}$ in the presence of $\mathrm{B}\left(\mathrm{C}_{6} \mathrm{~F}_{5}\right)_{3}$-derived FLPs has been utilized to effect the metal-free hydrogenation of $\mathrm{CO}_{2}$ to $\mathrm{CH}_{3} \mathrm{OH}^{10}$ and of organics such as nitriles/imines to their corresponding amines. ${ }^{11}$

The strength of a Lewis acid has been shown to correlate with chemical activity in certain processes, for example, the rate of epoxide ring-opening. ${ }^{4 a, 12}$ Simple steric and electronic

Received: June 1, 2011

Published: July 25, 2011 
modification of the Lewis acid $\mathrm{B}\left(\mathrm{C}_{6} \mathrm{~F}_{5}\right)_{3}$ has resulted in changes in catalytic reactivity. For instance, employing the bulkier B$\left(\mathrm{C}_{6} \mathrm{~F}_{5}\right)_{2}(\mathrm{Mes})\left(\mathrm{Mes}=2,4,6-\mathrm{Me}_{3} \mathrm{C}_{6} \mathrm{H}_{2}\right)$ has been recently shown to lead to orthogonal reactivity patterns in the FLP-mediated reduction of imines, ${ }^{13}$ and use of $\mathrm{B}\left(\mathrm{C}_{6} \mathrm{~F}_{5}\right)_{2} \mathrm{Ph}$ has altered the predominant mechanism in the allylstannation of aldehydes, relative to the perfluorophenyl counterpart. ${ }^{2 \mathrm{~d}}$ The majority of powerful boron-based Lewis acid systems have been formulated upon electron-withdrawing fluoroaryl ligands, ${ }^{14}$ which impart strong acidity at the acceptor site. However, while the high electronegativity of $\mathrm{F}\left(\chi_{\text {Pauling }}=3.98\right)$ ensures potent inductive withdrawal via the $\sigma$-bonds from the boron center, mesomeric donation from ortho- and para-F lone pairs is particularly effective ( $2 p-2 p$ overlap); this results in significant back-donation from the aromatic $\pi$-system into the acceptor orbital and can attenuate Lewis acidity. The degree to which $\pi$-electrons from aryl substituents are involved with the aromatic nucleus may be quantified using the Hammett equation, which derives a free energy relationship between reaction rates and equilibrium constants for various meta- and para- substituted aromatic compounds; ${ }^{15}$ more positive values denote increasingly powerful electron-withdrawing groups, in the absence of steric effects. While $\mathrm{Cl}$ is not as electronegative as $\mathrm{F}\left(\chi_{\text {Pauling }}=3.16\right)$, its Hammett parameter $\left(\sigma_{\text {para }} \mathrm{Cl}=0.227\right)$ is substantially greater $\left(\sigma_{\text {para }} \mathrm{F}=0.062\right)$ as a result of weaker $(3 p-2 p) \pi$-overlap with the aromatic nucleus. Accordingly, substitution of $\mathrm{C}_{6} \mathrm{~F}_{5}$ for perchlorophenyl groups $\left(\mathrm{C}_{6} \mathrm{Cl}_{5}\right)$ should increase the inherent electronwithdrawing properties of the ligands in the resultant organoboranes, a factor which should result in an increase in Lewis acidity when considered alone.

In this study, the synthesis of a systematic series of new (perhaloaryl)borane Lewis acids $\mathrm{B}\left(\mathrm{C}_{6} \mathrm{~F}_{5}\right)_{3-n}\left(\mathrm{C}_{6} \mathrm{Cl}_{5}\right)_{n}(n=1-3)$ is reported, to comprehensively examine the effects on the spectroscopic and electrochemical properties upon replacement of $\mathrm{C}_{6} \mathrm{~F}_{5}$ with $\mathrm{C}_{6} \mathrm{Cl}_{5}$ moieties. In addition, the trends in the Lewis acidity of these boranes with the parent $\mathrm{B}\left(\mathrm{C}_{6} \mathrm{~F}_{5}\right)_{3}$ are examined, using established donor-acceptor methods, which are contrasted with their electrochemical behavior.

\section{RESULTS AND DISCUSSION}

Synthesis. Commonly used reagents for the introduction of aryl substituents onto main group metal halides are organolithium and Grignard reagents. ${ }^{16}$ For example, the synthesis of $\mathrm{B}\left(\mathrm{C}_{6} \mathrm{~F}_{5}\right)_{3}$ is achieved by treating a boron trihalide (typically $\mathrm{BF}_{3} \cdot \mathrm{OEt}_{2}$ or $\mathrm{BCl}_{3}$ ) with either $\mathrm{C}_{6} \mathrm{~F}_{5} \mathrm{MgBr}$ or $\mathrm{C}_{6} \mathrm{~F}_{5} \mathrm{Li}^{1 \mathrm{a}}{ }^{1 \mathrm{a}}$ the latter requires caution in handling since it is can become explosive above $-30{ }^{\circ} \mathrm{C}$. Use of donor solvents, e.g. $\mathrm{Et}_{2} \mathrm{O}$ or THF are usually avoided if the anionic synthon can be prepared in nonpolar media since, if the borane coordinates to the solvent, a final sublimation step may be required to isolate the free Lewis acid, e.g. $\mathrm{C}_{6} \mathrm{~F}_{5} \mathrm{MgBr}$ and $\mathrm{Et}_{2} \mathrm{O} \cdot \mathrm{BF}_{3}$ react in $\mathrm{Et}_{2} \mathrm{O}$ to form diethyl etherate complex, $\mathrm{Et}_{2} \mathrm{O} \cdot \mathrm{B}\left(\mathrm{C}_{6} \mathrm{~F}_{5}\right)_{3}$. Unfortunately, highly polar organometallic reagents often exhibit poor selectivity and cannot be used to synthesize partially perfluoroarylated boranes, e.g. $\mathrm{B}\left(\mathrm{C}_{6} \mathrm{~F}_{5}\right)_{2} \mathrm{Cl}$, irrespective of the stoichiometry used. For this purpose, less reactive and more selective reagents such as $\mathrm{Me}_{2} \mathrm{Sn}\left(\mathrm{C}_{6} \mathrm{~F}_{5}\right)_{2}$ and $\mathrm{CuC}_{6} \mathrm{~F}_{5}$ have been used in conjunction with $\mathrm{BX}_{3}(\mathrm{X}=\mathrm{Cl}, \mathrm{Br})$ to exercise greater control in halide metathesis reactions. ${ }^{17}$ Perchlorophenyllithium $\left(\mathrm{C}_{6} \mathrm{Cl}_{5} \mathrm{Li}\right)$, synthesized in a facile manner from ${ }^{n} \mathrm{BuLi}$ and $\mathrm{C}_{6} \mathrm{Cl}_{6}$ in $\mathrm{Et}_{2} \mathrm{O}$, is reported to
Scheme 1. Synthesis of $B\left(C_{6} C l_{5}\right)\left(C_{6} F_{5}\right)_{2}$ (3)

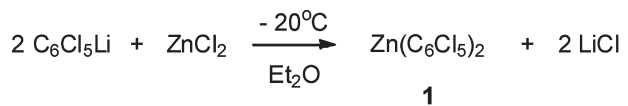

$$
\begin{aligned}
& 1+\text { excess } \mathrm{BBr}_{3} \underset{\text { Toluene }}{\stackrel{100^{\circ} \mathrm{C}}{\longrightarrow}} 2\left(\mathrm{C}_{6} \mathrm{Cl}_{5}\right) \mathrm{BBr}_{2}+\mathrm{ZnBr}_{2} \\
& 2 \\
& 2+2 \mathrm{CuC}_{6} \mathrm{~F}_{5} \underset{\text { Toluene }}{\stackrel{60^{\circ} \mathrm{C}}{\longrightarrow}} \mathrm{B}\left(\mathrm{C}_{6} \mathrm{Cl}_{5}\right)\left(\mathrm{C}_{6} \mathrm{~F}_{5}\right)_{2}
\end{aligned}
$$

decompose only slowly between 0 and $-10^{\circ} \mathrm{C}$, and its stability is thus appreciably greater than that of $\mathrm{C}_{6} \mathrm{~F}_{5} \mathrm{Li}^{18}$

Retrosynthetic analysis of the target compounds $\mathrm{B}\left(\mathrm{C}_{6} \mathrm{~F}_{5}\right)_{n^{-}}$ $\left(\mathrm{C}_{6} \mathrm{Cl}_{5}\right)_{3-n}(n=1,2)$ reveals two plausible routes to their formation, depending on which perhaloaryl groups are installed onto boron first. It was reasoned that $\mathrm{B}-\mathrm{X}$ metathesis with the smaller $\mathrm{C}_{6} \mathrm{~F}_{5}$ group on a $\mathrm{B}\left(\mathrm{C}_{6} \mathrm{Cl}_{5}\right)_{n} \mathrm{X}_{3-n}(n=1,2 ; \mathrm{X}=\mathrm{Cl}, \mathrm{Br})$ intermediate should be performed at the final stage of the synthesis in order to minimize potential side-reactions, that is, para-F substitution $\left(\mathrm{S}_{\mathrm{N}} \mathrm{Ar}\right)$ on $\mathrm{C}_{6} \mathrm{~F}_{5}$ rings, which has been documented for $\mathrm{B}\left(\mathrm{C}_{6} \mathrm{~F}_{5}\right)_{3}$ in reaction with bulky nucleophiles. ${ }^{19}$ $\left(\mathrm{C}_{6} \mathrm{Cl}_{5}\right) \mathrm{BCl}_{2}$ has been previously synthesized from $\mathrm{C}_{6} \mathrm{Cl}_{5} \mathrm{SnMe}_{3}$ and $\mathrm{BCl}_{3(\mathrm{~g})}$ at $120{ }^{\circ} \mathrm{C}^{20}$ Attempts to perform this reaction using a less hazardous solution-phase protocol $\left(\mathrm{BCl}_{3}\right.$ is available commercially in heptane) surprisingly led to no reaction. An alternative route, avoiding toxic organotin species, was thus developed. Realizing the potential of $\mathrm{Zn}\left(\mathrm{C}_{6} \mathrm{~F}_{5}\right)_{2}$ to selectively transfer $\mathrm{C}_{6} \mathrm{~F}_{5}$ groups to organoboron halides, ${ }^{21}$ base-free $\mathrm{Zn}$ $\left(\mathrm{C}_{6} \mathrm{Cl}_{5}\right)_{2}(\mathbf{1})$ was synthesized in a facile manner from $\mathrm{C}_{6} \mathrm{Cl}_{5} \mathrm{Li}$ and $\mathrm{ZnCl}_{2} .1$ is poorly soluble in nondonor solvents yet reaction with excess $\mathrm{BBr}_{3}$ in toluene leads to transfer of both aryl groups from $\mathrm{Zn}$, cleanly affording $\mathrm{C}_{6} \mathrm{Cl}_{5} \mathrm{BBr}_{2}(2)$ in good yield and on a multigram scale (Scheme 1); using the less vigorous Lewis acid $\mathrm{BCl}_{3}$ leads to a significantly slower reaction.

2 is a highly moisture sensitive solid, producing $\mathrm{HBr}$ fumes in air; nonetheless it is more easily handled than $\mathrm{C}_{6} \mathrm{~F}_{5} \mathrm{BBr}_{2}$, which is an oil. Attempts to react $\mathrm{C}_{6} \mathrm{~F}_{5} \mathrm{Li}$ or $\mathrm{C}_{6} \mathrm{~F}_{5} \mathrm{MgBr}$ with 2 in $\mathrm{Et}_{2} \mathrm{O}$ led to products of solvent cleavage, identified by several quartet resonances between 3 and $4 \mathrm{ppm}$ and corresponding triplets at higher field ( $\left.{ }^{1} \mathrm{H} \mathrm{NMR}\right)$, and by $\mathrm{MS}$ which revealed ion peaks attributable to $\mathrm{B}\left(\mathrm{C}_{6} \mathrm{Cl}_{5}\right)\left(\mathrm{C}_{6} \mathrm{~F}_{5}\right) \mathrm{OEt}$ and $\mathrm{B}\left(\mathrm{C}_{6} \mathrm{Cl}_{5}\right)(\mathrm{OEt})_{2}$; it was subsequently discovered that 2 reacts with $\mathrm{Et}_{2} \mathrm{O}$ alone to form various $\mathrm{B}$-OEt containing species. Jäkle et al. have reported the enhanced selectivity exhibited by $\mathrm{CuAr}\left(\mathrm{Ar}=\mathrm{C}_{6} \mathrm{~F}_{5}\right.$, Mes $)$ in conjunction with $\mathrm{BX}_{3}(\mathrm{X}=\mathrm{Cl}, \mathrm{Br})$ to form $\mathrm{ArBX}_{2}$ or $\mathrm{Ar}_{2} \mathrm{BX}$, in comparison with their lithium or Grignard analogues; furthermore, these reactions can be conducted in donor-free solvents such as $\mathrm{CH}_{2} \mathrm{Cl}_{2}$ and aromatics. ${ }^{17 \mathrm{c}}$ Gratifyingly, metathesis using two equivalents of $\mathrm{CuC}_{6} \mathrm{~F}_{5}$ with 2 in toluene afforded $\mathrm{B}\left(\mathrm{C}_{6} \mathrm{Cl}_{5}\right)$ $\left(\mathrm{C}_{6} \mathrm{~F}_{5}\right)_{2}(3)$ as a white powdery solid, in excellent yield $(81 \%)$ after vacuum sublimation. 3 is moderately soluble in aliphatic hydrocarbons, yet highly so in aromatics and chlorinated solvents. It is also stable to oxygen, but binds $\mathrm{H}_{2} \mathrm{O}$ forming the dative complex $\mathrm{H}_{2} \mathrm{O} \cdot[3]$ as shown by ${ }^{19} \mathrm{~F} \mathrm{NMR}$, ${ }^{22}$ which is a sensitive tool in determining the coordination environment around the boron center in $\mathrm{C}_{6} \mathrm{~F}_{5}$-substituted boranes. ${ }^{23}$ Interestingly, and 


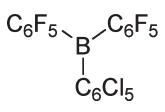

3

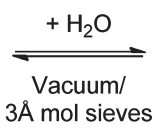

$-\mathrm{H}_{2} \mathrm{O}$

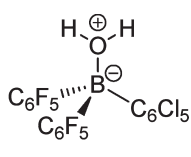

$\mathrm{H}_{2} \mathrm{O} \cdot[3]$
Figure 1. Reversible coordination of $\mathrm{H}_{2} \mathrm{O}$ by 3 .

Scheme 2. Synthesis of $\left(\mathrm{C}_{6} \mathrm{Cl}_{5}\right)_{2} \mathrm{BCl}$ (4)

$$
2 \mathrm{C}_{6} \mathrm{Cl}_{5} \mathrm{Li}+\mathrm{BCl}_{3} \stackrel{\mathrm{Et}_{2} \mathrm{O} / \text { hexane }}{\longrightarrow}\left(\mathrm{C}_{6} \mathrm{Cl}_{5}\right)_{2} \mathrm{BCl}+2 \mathrm{LiCl}
$$

4

Scheme 3. Synthesis of $B\left(\mathrm{C}_{6} \mathrm{Cl}_{5}\right)_{2}\left(\mathrm{C}_{6} \mathrm{~F}_{5}\right)$ (5)

$$
4+\mathrm{CuC}_{6} \mathrm{~F}_{5} \underset{\substack{\text { Toluene } \\ \text { 3 days }}}{\stackrel{80^{\circ} \mathrm{C}}{\longrightarrow}} \quad \mathrm{B}\left(\mathrm{C}_{6} \mathrm{Cl}_{5}\right)_{2}\left(\mathrm{C}_{6} \mathrm{~F}_{5}\right)
$$

in contrast to $\mathrm{H}_{2} \mathrm{O} \cdot \mathrm{B}\left(\mathrm{C}_{6} \mathrm{~F}_{5}\right)_{3}$, the $\mathrm{H}_{2} \mathrm{O}$ molecule can be rapidly and reversibly removed under vacuum, or in the solution phase upon addition of molecular sieves, forming 3 (Figure 1). This difference is likely to be the result of increased steric bulk around the boron center due to the ortho-Cl substituents, as opposed to electronic effects (vide infra), leading to a longer and thus weaker $\mathrm{B}-\mathrm{O}$ interaction.

The synthesis of $\mathrm{B}\left(\mathrm{C}_{6} \mathrm{Cl}_{5}\right)_{2}\left(\mathrm{C}_{6} \mathrm{~F}_{5}\right)$ required a previously unreported $\left(\mathrm{C}_{6} \mathrm{Cl}_{5}\right)_{2} \mathrm{BX}(\mathrm{X}=\mathrm{Cl}, \mathrm{Br})$ reagent, and surprisingly, it was found that slow addition of hexane to $\mathrm{C}_{6} \mathrm{Cl}_{5} \mathrm{Li}\left(\mathrm{Et}_{2} \mathrm{O}\right.$ solution) resulted in the precipitation of a flocculent solid, presumably $\mathrm{C}_{6} \mathrm{Cl}_{5} \mathrm{Li} \cdot\left(\mathrm{OEt}_{2}\right)_{n}$, reaction of which with $\mathrm{BCl}_{3}$ furnished base-free $\left(\mathrm{C}_{6} \mathrm{Cl}_{5}\right)_{2} \mathrm{BCl}(4)$ in $54 \%$ yield (Scheme 2). In the absence of this heterogenization step significant $\mathrm{Et}_{2} \mathrm{O}$ cleavage products, as ascertained by ${ }^{1} \mathrm{H}$ NMR, were obtained. Conversely, the fluorinated analogue $\left(\mathrm{C}_{6} \mathrm{~F}_{5}\right)_{2} \mathrm{BCl}$ cannot be selectively obtained from $\mathrm{C}_{6} \mathrm{~F}_{5} \mathrm{M}(\mathrm{M}=\mathrm{Li}$ or $\mathrm{MgBr})$; it is prepared most expediently through $\mathrm{Sn}$-aryl cleavage of $\mathrm{Me}_{2} \mathrm{Sn}$ $\left(\mathrm{C}_{6} \mathrm{~F}_{5}\right)_{2}$ with $\mathrm{BCl}_{3}$ at elevated temperatures. ${ }^{17 \mathrm{~b}}$ It is anticipated that the greater steric bulk of $\mathrm{C}_{6} \mathrm{Cl}_{5}$ compared with $\mathrm{C}_{6} \mathrm{~F}_{5}$ is likely to permit greater control in this metathesis reaction. $\mathbf{4}$ is a paleorange crystalline solid which fumes slowly in moist air (releasing $\mathrm{HCl}$ ) and demonstrates a moderate solubility in chlorinated solvents, yet poor in aliphatics and aromatics.

Following the successful use of $\mathrm{CuC}_{6} \mathrm{~F}_{5}$ in the formation of 3 , its reaction with 4 led to the production of $\mathrm{B}\left(\mathrm{C}_{6} \mathrm{Cl}_{5}\right)_{2}\left(\mathrm{C}_{6} \mathrm{~F}_{5}\right)$ (5) in good yield, albeit after $72 \mathrm{~h}$ (Scheme 3 ). The slower rate of this transformation likely reflects the increased bulk of the starting haloborane 4 , and the replacement of a stronger $\mathrm{B}-\mathrm{Cl}$ bond as opposed to $\mathrm{B}-\mathrm{Br}$, in 2.

The synthesis of tris(pentachlorophenyl)borane was achieved through the stoichiometric addition of $\mathrm{BCl}_{3}$ to $\mathrm{C}_{6} \mathrm{Cl}_{5} \mathrm{Li}(1: 3)$, using hexane cosolvent as in the preparation of 4 , which is presumed to be an intermediate in the reaction. Accordingly $\mathrm{B}\left(\mathrm{C}_{6} \mathrm{Cl}_{5}\right)_{3}(\mathbf{6})$ was isolated in moderate yield (Scheme 4).

Compound $\mathbf{6}$ is air-stable, allowing for a facile workup by quenching unreacted $\mathrm{BCl}_{3}$ and $\mathrm{C}_{6} \mathrm{Cl}_{5} \mathrm{Li}$ with $\mathrm{H}_{2} \mathrm{O}$ and extracting with $\mathrm{CH}_{2} \mathrm{Cl}_{2}$ using 'open bench' techniques. Recrystallization from boiling toluene afforded $\mathbf{6 \cdot ( t o l u e n e )}$ as a pale-yellow microcrystalline solid; the solvent may be removed upon heating
Scheme 4. Synthesis of $\mathrm{B}\left(\mathrm{C}_{6} \mathrm{Cl}_{5}\right)_{3}(6)$

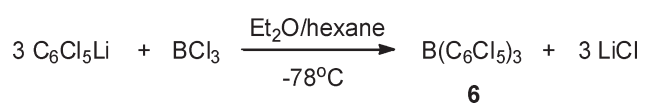

in vacuo. 6 is insoluble in aliphatic hydrocarbons, slightly so in aromatics and moderately in $\mathrm{CH}_{2} \mathrm{Cl}_{2}$. It is remarkably robust, remaining unchanged at temperatures up to $250{ }^{\circ} \mathrm{C}$ and does not sublime, even under high-vacuum $\left(1 \times 10^{-6} \mathrm{mbar}\right)$, at these temperatures. Refluxing 6 in a toluene $/ \mathrm{H}_{2} \mathrm{O}$ mixture (1:1) for several days led to quantitative reclamation of the compound and thus demonstrates an impressive hydrolytic stability.

Structural Characterization. Crystals of 3 suitable for single crystal X-ray structure determination were grown through slowcooling of a saturated toluene solution to $-35^{\circ} \mathrm{C}$, ${ }^{24}$ while for $6 \cdot$ toluene clear prisms were obtained from a saturated solution in boiling toluene (in air) that was slowly cooled to ambient temperature. Slow evaporation of a toluene solution of 5 afforded small pale-yellow blocks. Crystallographic data are enclosed in Table 1 while the solid-state structures are shown in Figures 2, 3 and 4 for 3, 5 and 6 respectively.

Despite finding widespread use as a Lewis acid in many chemical applications, for example, activator for metallocenemediated olefin polymerizations, no structural data exist for $\mathrm{B}\left(\mathrm{C}_{6} \mathrm{~F}_{5}\right)_{3}$. Compounds $\mathrm{B}\left(\mathrm{C}_{6} \mathrm{~F}_{5}\right)_{3-n}\left(\mathrm{C}_{6} \mathrm{Cl}_{5}\right)_{n}(n=1-3)$ represent the first structurally characterized compounds featuring the $\mathrm{B}-\mathrm{C}_{6} \mathrm{Cl}_{5}$ motif; all three crystallize in centrosymmetric space groups so that both left and right-handed "propellers" are present. $^{25}$ The coordination environment about B is trigonal planar as judged by the almost zero deviation of this atom from the plane of three ipso-C atoms, in spite of 3, 5 and 6 having different ligand sets. ${ }^{26,27}$ Table 2 shows selected bond lengths and torsion angles for all three compounds. The $\mathrm{C}-\mathrm{Cl}$ bond lengths vary little and are very similar to those in $\mathrm{C}_{6} \mathrm{Cl}_{6}$ (range 1.713(2) $-1.724(3) \AA) ;{ }^{28}$ the longest are found in the ortho position and are likely to reflect the high steric crowding at these sites.

In 3 the two $\mathrm{C}_{6} \mathrm{~F}_{5}$ rings are inequivalent, which is also found in the analogous $\operatorname{ArB}\left(\mathrm{C}_{6} \mathrm{~F}_{5}\right)_{2}\left(\mathrm{Ar}=\mathrm{C}_{6} \mathrm{H}_{5}\right.$, Mes $)$ species; ${ }^{29}$ the torsion angles between the best plane of a $\mathrm{C}_{6} \mathrm{~F}_{5}$ ring and the plane of the remaining B-ipso $\left(\mathrm{C}_{6} \mathrm{X}_{5}\right)_{2}(\mathrm{X}=\mathrm{Cl}, \mathrm{F})$ fragment (see Figure 5 for definition) best represent this difference. The lowest energy conformation (minimizing nonbonding interactions between ortho-substituents on different rings) would be a 'propeller' for steric reasons, for which each $\mathrm{Ar}^{\mathrm{X} \wedge} \mathrm{BAr}_{2}=60^{\circ}\left(\mathrm{Ar}^{\mathrm{X}}=\right.$ $\left.\mathrm{C}_{6} \mathrm{Cl}_{5}, \mathrm{C}_{6} \mathrm{~F}_{5}\right) .{ }^{30}$ However, $\pi$-donation from the $\mathrm{C}_{6} \mathrm{~F}_{5}$ rings into the vacant $\mathrm{B} p$-orbital lowers the energy of the molecule and a compromise is achieved; accordingly the aryl group with the smallest torsion angle also has the shortest $\mathrm{B}$-ipso $\mathrm{C}$ bond for each $\operatorname{ArB}\left(\mathrm{C}_{6} \mathrm{~F}_{5}\right)_{2}\left(\mathrm{Ar}=\mathrm{C}_{6} \mathrm{H}_{5}, \mathrm{Mes}, \mathrm{C}_{6} \mathrm{Cl}_{5}\right)$ examined. By comparison, the much larger torsion angle for $\mathrm{C}_{6} \mathrm{Cl}_{5}$ in 3 is likely to be due to the poorer $\pi$-donor ability of this substituent relative to $\mathrm{C}_{6} \mathrm{~F}_{5}$, in addition to its larger size; for 6 , the angles now approach $D_{3}$ symmetry.

NMR Spectroscopy. The ${ }^{19} \mathrm{~F},{ }^{11} \mathrm{~B}$ and ${ }^{13} \mathrm{C}$ NMR spectral data for 3, 5 and 6 in the solution phase have been summarized and compared with $\mathrm{B}\left(\mathrm{C}_{6} \mathrm{~F}_{5}\right)_{3}$ (Tables 3 and 4). Compounds 3 and 5 display three resonances in their ${ }^{19} \mathrm{~F}$ NMR spectra in an intensity ratio 2:1:2 for the corresponding ortho, para and meta fluorine environments (to higher field respectively) for the $\mathrm{C}_{6} \mathrm{~F}_{5}$ rings. The difference between shifts for the para and meta environments, $\Delta \delta_{\mathrm{m}, \mathrm{p}}$, are between 17 and $18.5 \mathrm{ppm}$ and, in 
Table 1. Crystallographic Data and Structure Refinement for Compounds 3, 5 and 6· Toluene

\begin{tabular}{|c|c|c|c|}
\hline & 3 & 5 & $6 \cdot$ toluene \\
\hline Empirical formula & $\mathrm{C}_{18} \mathrm{BCl}_{5} \mathrm{~F}_{10}$ & $\mathrm{C}_{18} \mathrm{BCl}_{10} \mathrm{~F}_{5}$ & $\mathrm{C}_{25} \mathrm{H}_{8} \mathrm{BCl}_{15}$ \\
\hline Formula weight & 594.25 & 676.53 & 850.94 \\
\hline Temperature & $150 \mathrm{~K}$ & $150 \mathrm{~K}$ & $150 \mathrm{~K}$ \\
\hline Wavelength & $0.71073 \AA$ & $0.71073 \AA$ & $0.71073 \AA$ \\
\hline Crystal system & Monoclinic & Triclinic & Triclinic \\
\hline Space group & $P 2_{1} / n$ & $P \overline{1}$ & $P \overline{1}$ \\
\hline \multirow[t]{3}{*}{ Unit cell dimensions } & $a=9.3745(2) \AA, \alpha=90^{\circ}$ & $a=9.6279(1) \AA, \alpha=69.5030(7)^{\circ}$ & $a=8.9324(2) \AA, \alpha=96.8119(7)^{\circ}$ \\
\hline & $b=14.6816(3) \AA, \beta=90.3251(10)^{\circ}$ & $b=11.0451(2) \AA, \beta=85.0590(7)^{\circ}$ & $b=13.3079(2) \AA, \beta=99.4211(8)^{\circ}$ \\
\hline & $c=14.5635(4) \AA, \gamma=90^{\circ}$ & $c=12.3145(3) \AA, \gamma=70.2181(11)^{\circ}$ & $c=13.4168(3) \AA, \gamma=90.0255(9)^{\circ}$ \\
\hline Volume & $2004.38(8) \AA^{3}$ & $1153.47(4) \AA^{3}$ & $1561.94(5) \AA^{3}$ \\
\hline$Z$ & 4 & 2 & 2 \\
\hline Density (calculated) & $1.969 \mathrm{Mg} / \mathrm{m}^{3}$ & $1.948 \mathrm{Mg} / \mathrm{m}^{3}$ & $1.809 \mathrm{Mg} / \mathrm{m}^{3}$ \\
\hline Absorption coefficient & $0.822 \mathrm{~mm}^{-1}$ & $1.257 \mathrm{~mm}^{-1}$ & $1.341 \mathrm{~mm}^{-1}$ \\
\hline$F(000)$ & 1152 & 656 & 836 \\
\hline Crystal size & $0.200 \times 0.180 \times 0.060 \mathrm{~mm}^{3}$ & $0.150 \times 0.080 \times 0.050 \mathrm{~mm}^{3}$ & $0.500 \times 0.300 \times 0.040 \mathrm{~mm}^{3}$ \\
\hline$\theta$ range for data collection & 5.160 to $27.497^{\circ}$ & 5.148 to $27.520^{\circ}$ & 5.118 to $27.472^{\circ}$ \\
\hline Index ranges & $\begin{array}{l}-12 \leq h \leq 12,0 \leq k \leq 19 \\
0 \leq l \leq 18\end{array}$ & $\begin{array}{l}-12 \leq h \leq 12,-14 \leq k \leq 14 \\
-15 \leq l \leq 15\end{array}$ & $\begin{array}{l}-11 \leq h \leq 11,-17 \leq k \leq 16 \\
-17 \leq l \leq 17\end{array}$ \\
\hline No. of reflns collected & 30894 & 20665 & 27296 \\
\hline No. of indep reflns & $4568[R($ int $)=0.029]$ & $5265[R($ int $)=0.024]$ & $7050[R($ int $)=0.031]$ \\
\hline Completeness to $\theta$ max & $99.3 \%$ & $99.2 \%$ & $99.0 \%$ \\
\hline Absorption correction & Semiempirical from equivalents & Semiempirical from equivalents & Semiempirical from equivalents \\
\hline Max. and min transmn & 0.95 and 0.79 & 0.94 and 0.88 & 0.95 and 0.78 \\
\hline Refinement method & Full-matrix least-squares on $F^{2}$ & Full-matrix least-squares on $F^{2}$ & Full-matrix least-squares on $F^{2}$ \\
\hline No. of data/restraints/params & $4567 / 0 / 308$ & $5265 / 0 / 307$ & $7050 / 256 / 435$ \\
\hline Goodness-of-fit on $F^{2}$ & 0.9445 & 0.9498 & 0.9641 \\
\hline Final $R$ indices $[I>2 \sigma(I)]$ & $R_{1}=0.0415, w R_{2}=0.0934$ & $R_{1}=0.0407, w R_{2}=0.1011$ & $R_{1}=0.0342, w R_{2}=0.0748$ \\
\hline$R$ indices (all data) & $R_{1}=0.0653, w R_{2}=0.1140$ & $R_{1}=0.0593, w R_{2}=0.1251$ & $R_{1}=0.0547, w R_{2}=0.0944$ \\
\hline Extinction coefficient & $141(15)$ & & $64(4)$ \\
\hline Largest diff peak and hole & 0.52 and $-0.57 \mathrm{e} / \AA^{3}$ & 0.61 and $-0.69 \mathrm{e} / \AA^{3}$ & 0.67 and $-0.67 \mathrm{e} / \AA^{3}$ \\
\hline
\end{tabular}

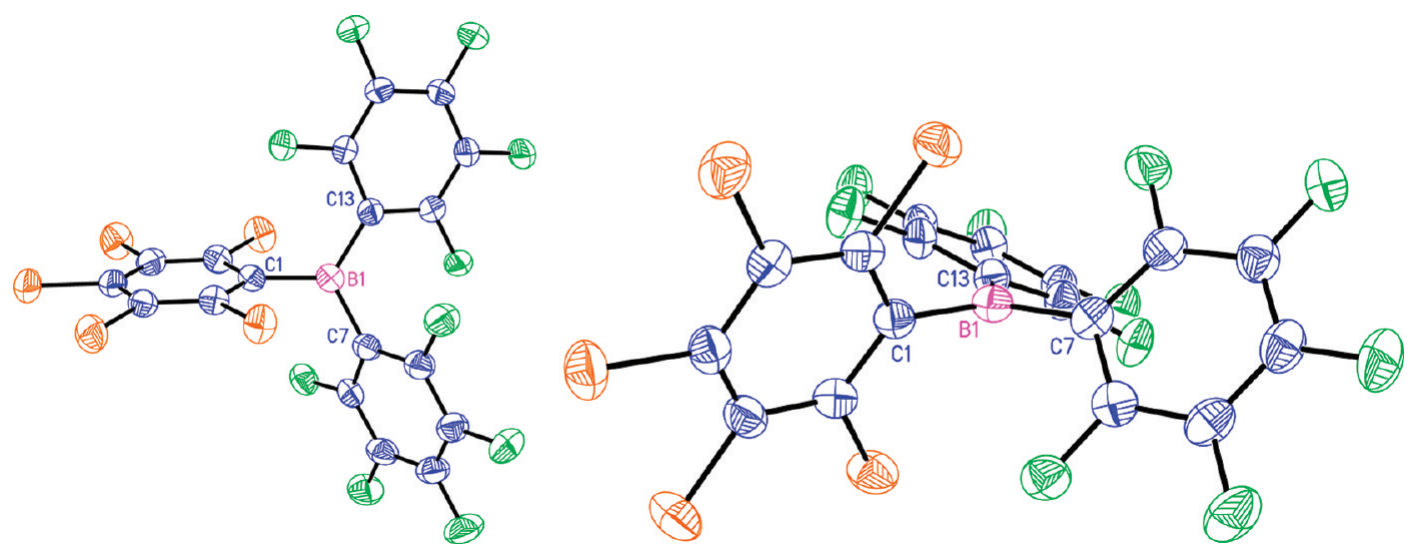

Figure 2. Structure of the right handed form of 3 . Orthogonal (left) and side (right) views of 3 (with respect to $\mathrm{BC}_{3}$ plane); thermal ellipsoids at $50 \%$ probability ( $\mathrm{C}$ atoms blue, $\mathrm{Cl}$ atoms orange, $\mathrm{F}$ atoms green and $\mathrm{B}$ atoms pink).

conjunction with ${ }^{11} \mathrm{~B}$ NMR data, support the premise that the boron retains the three coordinate geometry in the solution phase for all three species. ${ }^{31}$

${ }^{11} \mathrm{~B}$ NMR chemical shift is determined by both diamagnetic $\left(\sigma^{\mathrm{d}}\right)$ and paramagnetic $\left(\sigma^{\mathrm{P}}\right)$ contributions. The electronic structure calculations (vide infra) enable us to deconvolute the contribution from each of these terms. In summary, the calculations reveal that an overall decrease of the total magnetic shielding constant, and hence an increase in the observed ${ }^{11} \mathrm{~B}$ chemical shift in the order $\mathrm{B}\left(\mathrm{C}_{6} \mathrm{~F}_{5}\right)_{3}<\mathrm{B}\left(\mathrm{C}_{6} \mathrm{~F}_{5}\right)_{2}\left(\mathrm{C}_{6} \mathrm{Cl}_{5}\right)<$ $\mathrm{B}\left(\mathrm{C}_{6} \mathrm{~F}_{5}\right)\left(\mathrm{C}_{6} \mathrm{Cl}_{5}\right)_{2}<\mathrm{B}\left(\mathrm{C}_{6} \mathrm{Cl}_{5}\right)_{3}$, is dominated by changes in the diamagnetic term. As the diamagnetic component is related 

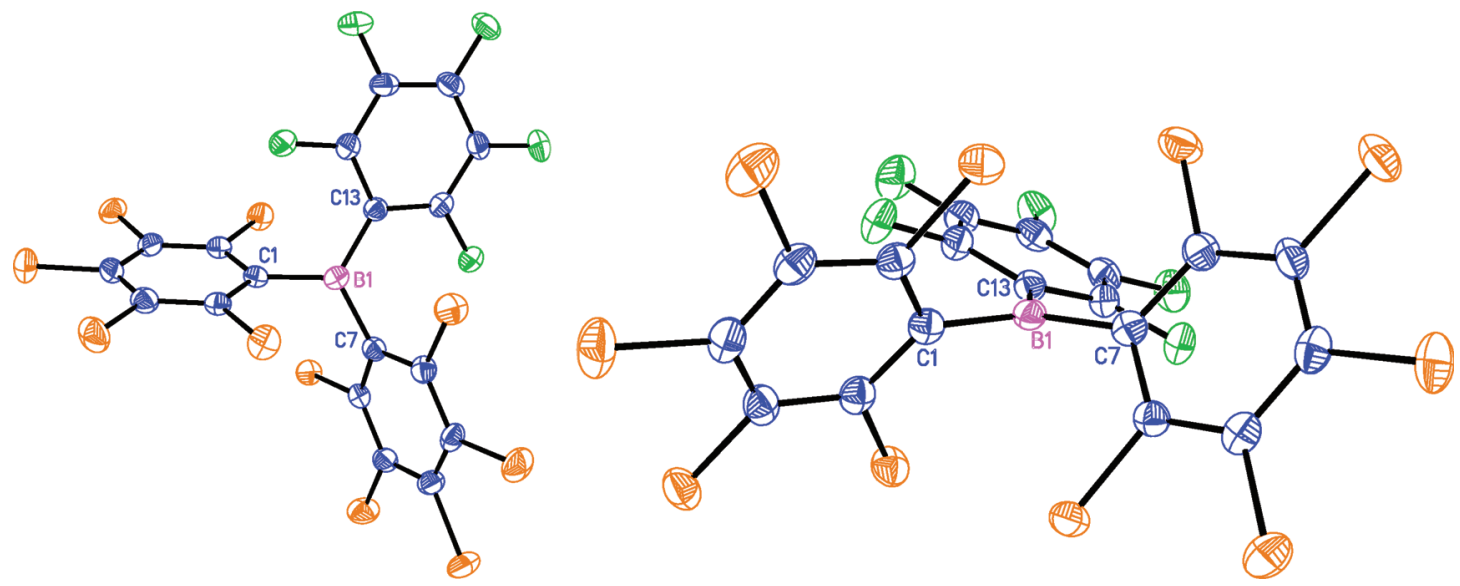

Figure 3. Structure of the right handed form of $\mathbf{5}$. Orthogonal (left) and side (right) views (with respect to $\mathrm{BC}_{3}$ plane); thermal ellipsoids at $50 \%$ probability ( $\mathrm{C}$ atoms blue, $\mathrm{Cl}$ atoms orange, $\mathrm{F}$ atoms green and $\mathrm{B}$ atoms pink).
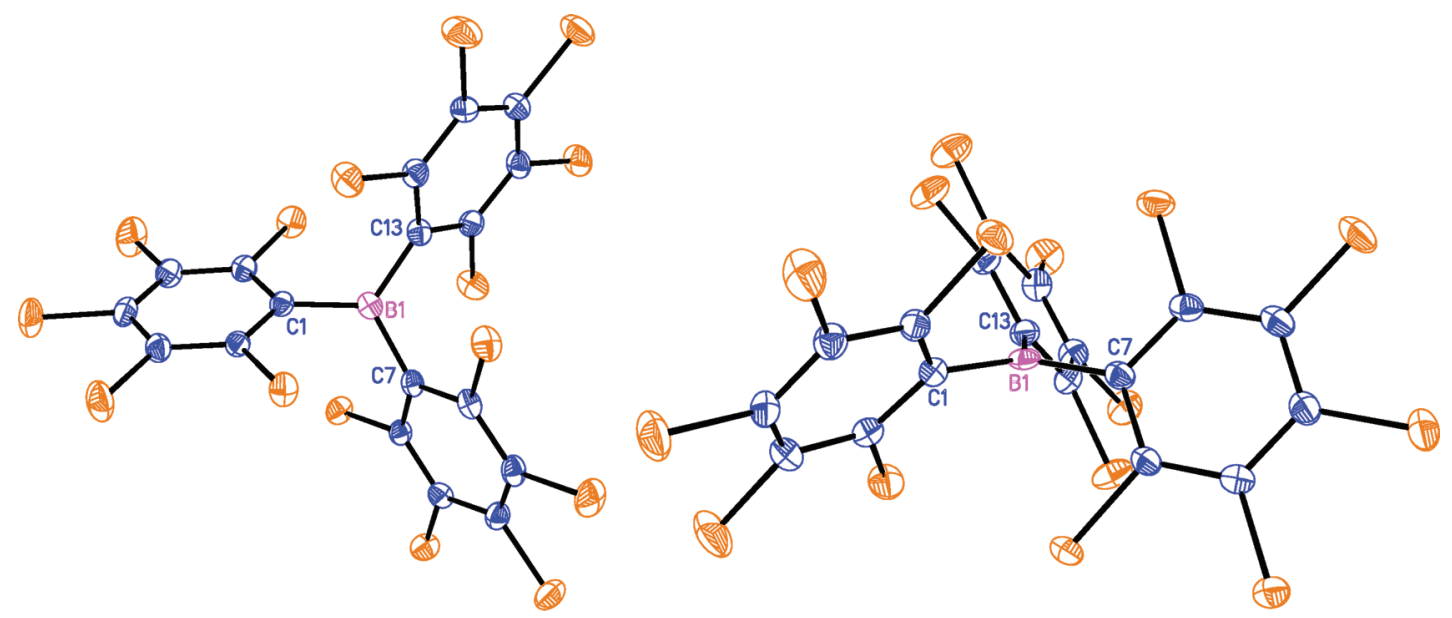

Figure 4. Structure of the right handed form of 6. Orthogonal (left) and side (right) views (with respect to $\mathrm{BC}_{3}$ plane); thermal ellipsoids at $50 \%$ probability ( $\mathrm{C}$ atoms blue, $\mathrm{Cl}$ atoms orange and $\mathrm{B}$ atoms pink). Disordered toluene molecule in asymmetric unit removed for clarity.

Table 2. Selected Bond Lengths and Angles for $\mathrm{B}\left(\mathrm{C}_{6} \mathrm{~F}_{5}\right)_{3}$ and Compounds 3,5 and $6^{a}$

\begin{tabular}{lllll} 
& \multicolumn{5}{c}{$\mathrm{B}\left(\mathrm{C}_{6} \mathrm{~F}_{5}\right)_{3-\mathrm{n}}\left(\mathrm{C}_{6} \mathrm{Cl}_{5}\right)_{\mathrm{n}} ; \mathrm{n}=0-3$} \\
\cline { 2 - 5 } & \multicolumn{1}{c}{$\mathrm{B}\left(\mathrm{C}_{6} \mathrm{~F}_{5}\right)_{3}$} & \multicolumn{1}{c}{3} & \multicolumn{1}{c}{5} & \multicolumn{1}{c}{6} \\
$\mathrm{~B} 1-\mathrm{C} 1(\AA)$ & {$[1.57]$} & $1.580(4)[1.59]$ & $1.589(4)[1.59]$ & $1.576(4)[1.59)$ \\
$\mathrm{B} 1-\mathrm{C} 7(\AA)$ & {$[1.57]$} & $1.577(4)[1.57]$ & $1.586(4)[1.59]$ & $1.587(4)[1.59]$ \\
$\mathrm{B} 1-\mathrm{C} 13(\AA)$ & {$[1.57]$} & $1.561(4)[1.57]$ & $1.552(4)[1.57]$ & $1.586(4)[1.59]$ \\
$\operatorname{Range} \mathrm{C}-\mathrm{F}(\AA)$ & {$[1.33-1.34]$} & $1.333(3)-1.352(4)[1.33-1.34]$ & $1.330(4)-1.344(3)[1.33-1.34]$ & - \\
$\operatorname{Range} \mathrm{C}-\mathrm{Cl}(\AA)$ & - & $1.712(3)-1.732(3)[1.74-1.76]$ & $1.714(3)-1.730(3)[1.74-1.76]$ & $1.711(3)-1.732(3)[1.74-1.75]$ \\
$\mathrm{Ar}^{\mathrm{F} \wedge} \operatorname{BAr}_{2}(\mathrm{deg})$ & {$[40,41,40]$} & $24.4,51.9[24,52]$ & $22.3[36]$ & - \\
$\operatorname{Ar}^{\mathrm{C} \wedge} \operatorname{BAr}_{2}(\mathrm{deg})$ & - & $69.7[74]$ & $57.1,62.0[57,58]$ & $54.5,55.3,58.1[53,53,53]$
\end{tabular}

${ }^{a}$ Numbers in parentheses are estimated standard uncertainties (esu). Computed values (B3LYP/TZVP) are shown in square brackets. $\mathrm{Ar}^{\mathrm{X} \wedge} \mathrm{BAr}_{2}$ $\left(\mathrm{Ar}^{\mathrm{Cl}}=\mathrm{C}_{6} \mathrm{Cl}_{5} ; \mathrm{Ar}^{\mathrm{F}}=\mathrm{C}_{6} \mathrm{~F}_{5}\right)$ is the torsion angle, as defined in Figure 5.

directly to the ground state electron density, we believe that the observed ${ }^{11} \mathrm{~B}$ chemical shift in these systems is a reasonable probe of the electron density at the boron nucleus. Thus, as the number of coordinated $\mathrm{C}_{6} \mathrm{Cl}_{5}$ ligands increases, the $\mathrm{B}$ center is becoming more electron deficient, corroborating the hypothesis that a $\mathrm{C}_{6} \mathrm{Cl}_{5}$ substituent is more electronegative than $\mathrm{C}_{6} \mathrm{~F}_{5}$.
Although the $\mathrm{Ar}^{\mathrm{F}}$ groups are inequivalent in the X-ray crystal structure for $3,{ }^{19} \mathrm{~F}$ NMR resonances for each $\mathrm{C}_{6} \mathrm{~F}_{5}$ ring show averaging of aryl substituents in solution at $298 \mathrm{~K}$. The perturbations in the ${ }^{19} \mathrm{~F}$ NMR chemical shifts are most pronounced upon the introduction of the first $\mathrm{C}_{6} \mathrm{Cl}_{5}$ group; thereafter, the effects diminish, while for the ${ }^{11} \mathrm{~B}$ NMR chemical shifts the greatest 
change occurs between compounds 3 and 5 . On replacement of one $\mathrm{C}_{6} \mathrm{~F}_{5}$ for $\mathrm{C}_{6} \mathrm{Cl}_{5}$ in $\mathrm{B}\left(\mathrm{C}_{6} \mathrm{~F}_{5}\right)_{3}$, a stronger electron-withdrawing effect is experienced by $\mathrm{B}$. In the ${ }^{13} \mathrm{C}$ NMR, we observe the biggest difference between the ipso- $\mathrm{C}_{6} \mathrm{~F}_{5}{ }^{13} \mathrm{C}$ NMR resonance for 3 and $5\left(\Delta \delta_{i}=+2.2\right)$, in comparison with $\mathrm{B}\left(\mathrm{C}_{6} \mathrm{~F}_{5}\right)_{3}$ and 3 $\left(\Delta \delta_{i}=-1.0\right)$. The corresponding changes in the ${ }^{13} \mathrm{C}$ NMR shifts for the remaining $\mathrm{C}_{6} \mathrm{~F}_{5}$ carbon atoms $\left(\Delta \delta_{\mathrm{o}}, \Delta \delta_{\mathrm{m}}\right.$ and $\Delta \delta_{\mathrm{p}}$; ortho, meta and para respectively) become much smaller as $n$ increases.

Electronic Structure Analysis. To explore the electronic consequences of successive replacement of $\mathrm{C}_{6} \mathrm{~F}_{5}$ with $\mathrm{C}_{6} \mathrm{Cl}_{5}$, we have optimized the structures of all four members of the series $\mathrm{B}\left(\mathrm{C}_{6} \mathrm{~F}_{5}\right)_{3-n}\left(\mathrm{C}_{6} \mathrm{Cl}_{5}\right)_{n}(n=0-3)$ using density functional theory (B3LYP/TZVP). The bond lengths and angles at the minimum energy structures (shown in parentheses in Table 2) are all fully consistent with the experimental data. Most significantly in the context of the present study, the $\mathrm{B}-\mathrm{C}_{6} \mathrm{~F}_{5}$ distances across the series are uniformly $0.02 \AA$ shorter than their $\mathrm{B}-\mathrm{C}_{6} \mathrm{Cl}_{5}$ counterparts. Computed ${ }^{11} \mathrm{~B}$ shielding constants also replicate the experimental trend almost quantitatively, with shifts (relative to $\mathrm{B}\left(\mathrm{C}_{6} \mathrm{~F}_{5}\right)_{3}, n=0$ ) of $-0.4,4.5$, and $6.6 \mathrm{ppm}$ (for $n=1,2$ and 3, respectively) c.f. values of $0.3,4.9$, and $7.1 \mathrm{ppm}$ from experiment (Table 3). The decomposition of the shielding into paramagnetic and diamagnetic components (see Supporting Information, Table S1) shows that the diamagnetic term is, in absolute terms, larger. The trend toward lower shielding across the series $\mathrm{B}$ $\left(\mathrm{C}_{6} \mathrm{~F}_{5}\right)_{3}>\mathrm{B}\left(\mathrm{C}_{6} \mathrm{~F}_{5}\right)_{2}\left(\mathrm{C}_{6} \mathrm{Cl}_{5}\right)>\mathrm{B}\left(\mathrm{C}_{6} \mathrm{~F}_{5}\right)\left(\mathrm{C}_{6} \mathrm{Cl}_{5}\right)_{2}>\mathrm{B}\left(\mathrm{C}_{6} \mathrm{Cl}_{5}\right)_{3}$ is dominated by changes in the diamagnetic component. The (negative) paramagnetic shielding constants show the opposite trend, increasing slightly across the series. Thus changes in the paramagnetic term actually attenuate the changes in the chemical shift, which would be even more pronounced in their absence.

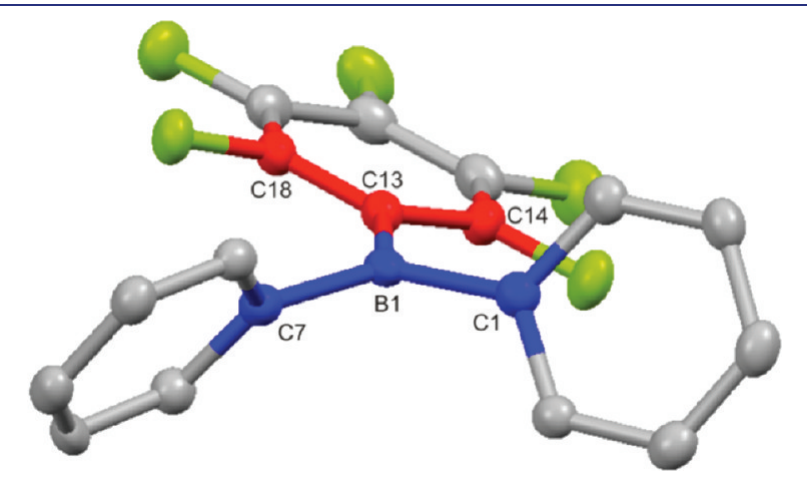

Figure 5. Calculation of the torsion angle for $\mathrm{C}_{6} \mathrm{~F}_{5}$ ring in 5 $\left(\mathrm{C}_{6} \mathrm{~F}_{5}{ }^{\wedge} \mathrm{BAr}_{2} ; \mathrm{Ar}=\mathrm{C}_{6} \mathrm{Cl}_{5}\right)$ and the $\mathrm{B}\left(\mathrm{C}_{6} \mathrm{Cl}_{5}\right)_{2}$ unit, defined as the angle between the planes of blue $\left(\mathrm{BAr}_{2}\right)$ atoms and red $\left(\mathrm{C}_{6} \mathrm{~F}_{5}\right.$ ring $)$ atoms. $\mathrm{F}$ atoms shown in green, $\mathrm{Cl}$ atoms have been omitted for clarity.
The encouraging level of agreement with both structural and spectroscopic observables gives us confidence that the chosen methodology is capturing the essential variations in electronic structure across the series. The computed natural charges on the boron center increase in the order $n=0(0.81)<n=1(0.89)<n$ $=2(1.02)<n=3(1.16)$, supporting the hypothesis that Lewis acidity increases with increasing substitution of $\mathrm{C}_{6} \mathrm{~F}_{5}$ with $\mathrm{C}_{6} \mathrm{Cl}_{5}$.

Kinetics of $\mathrm{H}_{2} \mathrm{O}$ Dissociation from $\mathrm{H}_{2} \mathrm{O} \cdot$ [3]. $\mathrm{H}_{2} \mathrm{O}$ forms a number of aqua complexes with $\mathrm{B}\left(\mathrm{C}_{6} \mathrm{~F}_{5}\right)_{3},\left[\mathrm{H}_{2} \mathrm{O} \cdot \mathrm{B}\left(\mathrm{C}_{6} \mathrm{~F}_{5}\right)_{3}\right]$. $\left(\mathrm{H}_{2} \mathrm{O}\right)_{n}$, involving $\mathrm{H}_{2} \mathrm{O}$ molecules hydrogen-bonded together beyond the primary coordination sphere of the dative $1: 1$ adduct. $^{32}$ Although coordinated water in $\mathrm{H}_{2} \mathrm{O} \cdot \mathrm{B}\left(\mathrm{C}_{6} \mathrm{~F}_{5}\right)_{3}$ is tightly bound and difficult to remove under vacuum (e.g., negligible loss at $10^{-3}$ mbar) or through heating (exceeding $60^{\circ} \mathrm{C}$ results in hydrolysis to $\left(\mathrm{C}_{6} \mathrm{~F}_{5}\right)_{2} \mathrm{BOH}$ and $\left.\mathrm{C}_{6} \mathrm{~F}_{5} \mathrm{H}\right){ }^{33}$ the kinetics of water dissociation have been studied by observing degenerate aqua ligand transfer between $\mathrm{H}_{2} \mathrm{O} \cdot \mathrm{B}\left(\mathrm{C}_{6} \mathrm{~F}_{5}\right)_{3}$ and free $\mathrm{B}\left(\mathrm{C}_{6} \mathrm{~F}_{5}\right)_{3}$ using VT ${ }^{19} \mathrm{~F} \mathrm{NMR}^{34}$ Since 3 exhibits reversible complexation of $\mathrm{H}_{2} \mathrm{O}$ under similar conditions it was thought prudent to determine comparable data for $\mathrm{H}_{2} \mathrm{O}$ dissociation from $\mathrm{H}_{2} \mathrm{O} \cdot[3]$; such a property is likely to be of use in true Lewis acid catalysis under aqueous regimes, in contrast to the Brønsted acidic properties of $\mathrm{H}_{2} \mathrm{O} \cdot \mathrm{B}\left(\mathrm{C}_{6} \mathrm{~F}_{5}\right)_{3}$ resulting from strong activation of the water molecule. ${ }^{35}$ Due to such facile decoordination of $\mathrm{H}_{2} \mathrm{O}$, an analogous equilibrium was achieved by combining 3 with $\mathrm{H}_{2} \mathrm{O}$ in a $2: 1$ ratio in $\mathrm{C}_{7} \mathrm{D}_{8}$ solution.

At $200 \mathrm{~K}$ a sharp ${ }^{19} \mathrm{~F}$ NMR spectrum is observed with separate resonances corresponding to a mixture of $\mathrm{H}_{2} \mathrm{O} \cdot[3]$ and 3 , whereas at room temperature dynamic averaging reflects fast exchange (Figures 6 and 7). Using line-shape analysis of the ${ }^{19} \mathrm{~F}$ NMR spectra as a function of temperature enabled the rate constants, and subsequent thermodynamic parameters $\Delta H^{\ddagger}$ and $\Delta S^{\ddagger}$, to be obtained from an Eyring plot (Table 5).

As anticipated, $\Delta H^{\ddagger}$ for dissociation of $\mathrm{H}_{2} \mathrm{O}$ from 3 is less than that for $\mathrm{B}\left(\mathrm{C}_{6} \mathrm{~F}_{5}\right)_{3}$, which is consistent with the increased steric profile of the borane due to the $\mathrm{C}_{6} \mathrm{Cl}_{5}$ group, leading to a weaker $\mathrm{B}-\mathrm{O}$ interaction. The considerably greater entropic value for $\mathrm{H}_{2} \mathrm{O} \cdot \mathrm{B}\left(\mathrm{C}_{6} \mathrm{~F}_{5}\right)_{3}$ may be rationalized by hydrogen-bonding between the hydroxyl protons and the ortho-F substituents; this

Table 4. ${ }^{13} \mathrm{C}$ NMR Spectral Data for $\mathrm{B}\left(\mathrm{C}_{6} \mathrm{~F}_{5}\right)_{3}$ and Compounds 3 and $5\left(\mathrm{C}_{6} \mathrm{~F}_{5}\right.$ Ligands Only)

\begin{tabular}{ccccc} 
& \multicolumn{4}{c}{$\delta\left({ }^{13} \mathrm{C} \mathrm{NMR}\right) / \mathrm{ppm}^{a}$} \\
\cline { 2 - 5 } $\mathrm{B}\left(\mathrm{C}_{6} \mathrm{~F}_{5}\right)_{3-n}\left(\mathrm{C}_{6} \mathrm{Cl}_{5}\right)_{n} ; n=0-2$ & ortho-C & para-C & meta-C & ipso-C \\
$\mathrm{B}\left(\mathrm{C}_{6} \mathrm{~F}_{5}\right)_{3}$ & 148.7 & 145.5 & 138.0 & 113.3 \\
3 & 149.6 & 145.9 & 138.0 & 112.3 \\
5 & 149.1 & 145.8 & 138.0 & 114.5
\end{tabular}

${ }^{a}$ Solvent: $\mathrm{CD}_{2} \mathrm{Cl}_{2}$ reference (internal).

\section{Table 3. ${ }^{19} \mathrm{~F}$ and ${ }^{11} \mathrm{~B}$ NMR Spectral Data for $\mathrm{B}\left(\mathrm{C}_{6} \mathrm{~F}_{5}\right)_{3}$ and Compounds 3, 5 and 6}

\begin{tabular}{|c|c|c|c|c|c|}
\hline \multirow[b]{2}{*}{$\mathrm{B}\left(\mathrm{C}_{6} \mathrm{~F}_{5}\right)_{3-n}\left(\mathrm{C}_{6} \mathrm{Cl}_{5}\right)_{n} ; n=0-3$} & \multicolumn{4}{|c|}{$\delta\left({ }^{19} \mathrm{~F}\right.$ NMR $) / \mathrm{ppm}^{a}$} & \multirow[b]{2}{*}{$\delta\left({ }^{11} \mathrm{~B}\right.$ NMR $) / \mathrm{ppm}^{c}$} \\
\hline & ortho-F & para-F & meta-F & $\Delta \delta_{\mathrm{m}, \mathrm{p}}{ }^{b}$ & \\
\hline $\mathrm{B}\left(\mathrm{C}_{6} \mathrm{~F}_{5}\right)_{3}$ & -128.2 & -143.9 & -161.1 & 17.2 & 61.2 \\
\hline 3 & -127.1 & -142.8 & -161.1 & 18.3 & 61.5 \\
\hline 5 & -127.4 & -143.1 & -160.6 & 17.5 & 66.1 \\
\hline 6 & - & - & - & - & 68.2 \\
\hline
\end{tabular}

${ }^{a}$ Solvent: $\mathrm{CD}_{2} \mathrm{Cl}_{2}, \mathrm{CFCl}_{3}$ reference (external). ${ }^{b}$ Difference between ${ }^{19} \mathrm{~F}$ NMR meta and para resonances $(\mathrm{ppm}) .{ }^{c} \mathrm{Solvent} \mathrm{CD}_{2} \mathrm{Cl}_{2}, \mathrm{BF}_{3} \cdot \mathrm{OEt}_{2}$ reference (external). 


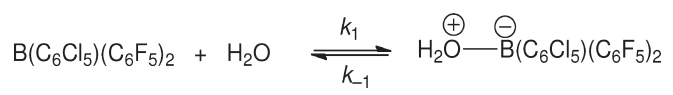

Figure 6. Dissociative exchange between $\mathrm{H}_{2} \mathrm{O}$ and 3 .

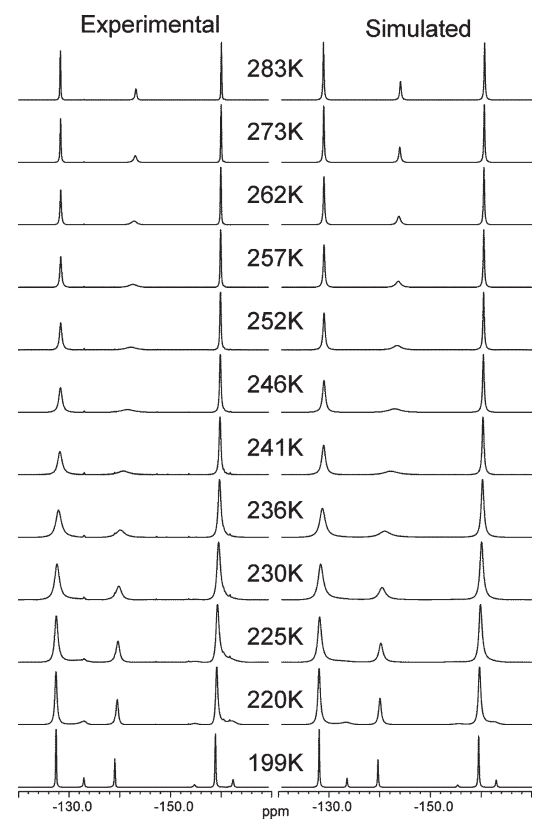

Figure 7. Variable-temperature ${ }^{19} \mathrm{~F}$ NMR spectra (simulated and experimental) for exchange of water between $\mathrm{H}_{2} \mathrm{O} \cdot[3]$ and $3\left(\mathrm{C}_{7} \mathrm{D}_{8}\right.$ solution).

Table 5. Activation Parameters for $\mathrm{H}_{2} \mathrm{O}$ Dissociation from $\mathrm{H}_{2} \mathrm{O} \cdot[\mathrm{B}]\left([\mathrm{B}]=\mathrm{B}\left(\mathrm{C}_{6} \mathrm{~F}_{5}\right)_{3}\right.$, and 3) as Determined by VT ${ }^{19} \mathrm{~F}$ $\operatorname{NMR}\left(\mathrm{C}_{7} \mathrm{D}_{8} \text { Solution }\right)^{a}$

\begin{tabular}{|c|c|c|c|}
\hline & $\begin{array}{c}\Delta H^{\ddagger} / \\
\mathrm{kcal} \mathrm{mol}^{-1}\end{array}$ & $\begin{array}{c}\Delta S^{\ddagger} / \\
\mathrm{cal} \mathrm{K}^{-1} \mathrm{~mol}^{-1}\end{array}$ & $\begin{array}{c}\Delta G_{300}^{\ddagger} / \\
\mathrm{kcal} \mathrm{mol}^{-1}\end{array}$ \\
\hline $\mathrm{H}_{2} \mathrm{O} \cdot \mathrm{B}\left(\mathrm{C}_{6} \mathrm{~F}_{5}\right)_{3}{ }^{34}$ & $19.0(3)$ & $24(1)$ & $11.4(1)$ \\
\hline $\mathrm{H}_{2} \mathrm{O} \cdot[3]$ & $9.9(0.3)$ & $3.2(1.2)$ & $8.9(1)$ \\
\hline
\end{tabular}

effect will be accentuated by the strong polarization of the $\mathrm{O}-\mathrm{H}$ bonds in the $\mathrm{H}_{2} \mathrm{O}$ molecule from the powerfully Lewis acidic organoborane fragment, and indeed $\mathrm{O}-\mathrm{H} \cdots \mathrm{F}$ bonding is observed in the solid-state structure of this compound. ${ }^{32 \mathrm{~b}}$ In the ground state of the complex, such organized bonding would likely restrict free rotation of bonds within the $\mathrm{H}_{2} \mathrm{O}$ moiety, thus lowering the total entropy of the system. However, upon $\mathrm{H}_{2} \mathrm{O}$ dissociation, loss of ordered $\mathrm{H}$-bonding leads to an overall greater entropy change than that expected for a unimolecular to bimolecular conversion alone. In contrast, for $\mathrm{H}_{2} \mathrm{O} \cdot[3]$, the degree of $\mathrm{O}-\mathrm{H} \cdots \mathrm{F}$ interactions is anticipated to be smaller due to fewer $\mathrm{C}_{6} \mathrm{~F}_{5}$ ligands in the borane and poorer $\mathrm{O}-\mathrm{H}$ polarization from weaker $\mathrm{H}_{2} \mathrm{O}-\mathrm{B}$ binding; therefore, upon dissociation, the entropy gain significantly diminishes in relation to that found for $\mathrm{H}_{2} \mathrm{O} \cdot \mathrm{B}\left(\mathrm{C}_{6} \mathrm{~F}_{5}\right)_{3}$.

Lewis Acidity Measurements of $\mathrm{B}\left(\mathrm{C}_{6} \mathrm{~F}_{5}\right)_{3-n}\left(\mathrm{C}_{6} \mathrm{Cl}_{5}\right)_{n}$. A number of methods to assess relative Lewis acidity have been developed and are commonly based on spectroscopic (IR, NMR) techniques. ${ }^{36}$ The first uses the Gutmann acceptor number (AN) which is calculated from the change in the ${ }^{31} \mathrm{P}$

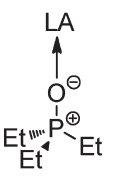

Gutmann

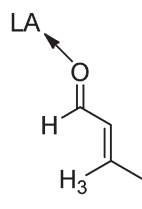

Childs
Figure 8. Gutmann and Childs Lewis acidity tests.

NMR chemical shift $(\Delta \delta)$ between free $\mathrm{Et}_{3} \mathrm{PO}$ and that of the $\mathrm{Et}_{3} \mathrm{PO}$-Lewis acid adduct, and has been subsequently modified by Beckett. ${ }^{36 e}$ The second method developed by Childs is based upon the downfield shift of the trans-crotonaldeyde $\mathrm{H}_{3}$ resonance upon complexation to the Lewis acid. ${ }^{36 a}$ This site is considered sterically remote from the site of bonding yet electronically connected via conjugation (Figure 8).

The results obtained are summarized in Table 6; for consistency, the Lewis acidity of $\mathrm{B}\left(\mathrm{C}_{6} \mathrm{~F}_{5}\right)_{3}$ has also been determined. The difference in chemical shift $\left(\Delta \delta^{31} \mathrm{P}\right.$ NMR $)$ upon reaction of $\mathrm{Et}_{3} \mathrm{PO}$ produces a trend that decreases in the order $\mathrm{B}\left(\mathrm{C}_{6} \mathrm{~F}_{5}\right)_{3}>3$ $>5$ and introduction of each $\mathrm{C}_{6} \mathrm{Cl}_{5}$ group has a linearly proportional effect on the measured Lewis acidity (Figure 9). for $\mathbf{6}$, no evidence of complexation was observed.

However, the Childs' method yielded a different set of results with the threshold for complex formation found to lie after compound 3 , and the upfield shift difference $(\Delta \delta)$ in the adduct markedly smaller than that seen for $\mathrm{B}\left(\mathrm{C}_{6} \mathrm{~F}_{5}\right)_{3}$.

Stephan et al. have recently documented the tuning of Lewis acidity for a series of phosphine-borane/phosphinium-borane species $\mathrm{R}_{2} \mathrm{P}\left(\mathrm{C}_{6} \mathrm{~F}_{4}\right) \mathrm{B}\left(\mathrm{C}_{6} \mathrm{~F}_{5}\right)_{2}$ and $\left[\mathrm{R}_{3} \mathrm{P}\left(\mathrm{C}_{6} \mathrm{~F}_{4}\right) \mathrm{B}\left(\mathrm{C}_{6} \mathrm{~F}_{5}\right)_{2}\right]^{+}$, observing a linear correlation between the two techniques. ${ }^{37}$ Selfconsistent results are obtained because, in addition to maintaining an environment consisting of only $\mathrm{B}-\mathrm{C}$ bonds, the site of electronic modulation is remote (para-bound $\mathrm{P}$ on $\mathrm{C}_{6} \mathrm{~F}_{4}$ ring) and the steric factors about the borane center remain essentially unchanged. Conversely, Britovsek et al. have synthesized the series $\mathrm{B}\left(\mathrm{C}_{6} \mathrm{~F}_{5}\right)_{3-x}\left(\mathrm{OC}_{6} \mathrm{~F}_{5}\right)_{x}(x=1-3)$, where systematic replacement of pentafluorophenyl groups by harder pentafluorophenoxy ligands results in an opposing binding preference for $\mathrm{Et}_{3} \mathrm{PO}$ over crotonaldehyde. ${ }^{38}$ This was rationalized using Pearson's HSAB principle ${ }^{39}$ where the largely covalent and softer $\mathrm{C}=\mathrm{O} p \pi-p \pi$ bond is a preferable donor to $\mathrm{B}\left(\mathrm{C}_{6} \mathrm{~F}_{5}\right)_{3}$ compared to the harder, more ionic $p \pi-d \tau \mathrm{P}=\mathrm{O}$ bond in $\mathrm{Et}_{3} \mathrm{P}=\mathrm{O}$, which is favored by $\mathrm{B}\left(\mathrm{OC}_{6} \mathrm{~F}_{5}\right)_{3}$.

In the latter study, as $x$ increases, a gradual increase in the accessibility of the Lewis acid site permits, in theory, binding by both donors surveyed (steric argument alone) thus allowing discrimination between Lewis bases on electronic factors resultant from replacement of $\mathrm{B}-\mathrm{C}$ by $\mathrm{B}-\mathrm{O}$ linkages. Examination of the space-fill diagrams for the solid-state structures of compounds 3, 5, and 6 (Figure 10) shows the enhanced screening of the boron acceptor site upon replacement of $\mathrm{C}_{6} \mathrm{~F}_{5}$ groups for $\mathrm{C}_{6} \mathrm{Cl}_{5}$.

Therefore, in determining the Lewis acidity of compounds on progressing from $\mathrm{B}\left(\mathrm{C}_{6} \mathrm{~F}_{5}\right)_{3}$ to $\mathrm{B}\left(\mathrm{C}_{6} \mathrm{Cl}_{5}\right)_{3}$, we examine a further permutation of variables, that of an increase in steric crowding concomitant with inherent electrophilicity of the boron center, while retaining a $\mathrm{B}-\mathrm{C}(\operatorname{aryl})_{3}$ core in each case. A steric threshold may be envisaged whereby non-bonded clashing between Lewis base and ortho-ring substituents prevents a dative interaction and overrides electronic factors; this is likely to be more prominent for crotonaldehyde $(\mathrm{C}=\mathrm{O} \text { bond length } 1.21 \AA)^{40}$ than the 
Table 6. ${ }^{31} \mathrm{P}$ and ${ }^{1} \mathrm{H}$ NMR Spectral Data Derived for Lewis Acidity Measurements for 3, 5, 6, and $\mathrm{B}\left(\mathrm{C}_{6} \mathrm{~F}_{5}\right)_{3}$

\begin{tabular}{|c|c|c|c|c|c|c|}
\hline \multirow[b]{2}{*}{ Lewis acid } & \multicolumn{4}{|c|}{$\mathrm{Et}_{3} \mathrm{PO}$} & \multicolumn{2}{|c|}{ trans-crotonaldeyde } \\
\hline & ${ }^{31} \mathrm{P} \mathrm{NMR} / \mathrm{ppm}^{a}$ & $\Delta \delta / \mathrm{ppm}^{b}$ & ${ }^{11} \mathrm{~B} \mathrm{NMR} / \mathrm{ppm}^{a}$ & $\mathrm{AN}^{b}$ & ${ }^{1} \mathrm{H} \mathrm{NMR} / \mathrm{ppm}^{a, c}$ & $\Delta \delta / \mathrm{ppm}^{c}$ \\
\hline none & 50.7 & - & - & 0 & 6.88 & - \\
\hline $\mathrm{B}\left(\mathrm{C}_{6} \mathrm{~F}_{5}\right)_{3}$ & 77.0 & 33.7 & -2.5 & 78.1 & 7.93 & 1.05 \\
\hline 3 & 75.8 & 32.5 & -1.1 & 75.3 & 7.51 & 0.63 \\
\hline 5 & 74.5 & 31.2 & 0.3 & 72.3 & 6.88 & - \\
\hline & 50.7 & 0.0 & 68.2 & - & 6.88 & - \\
\hline
\end{tabular}

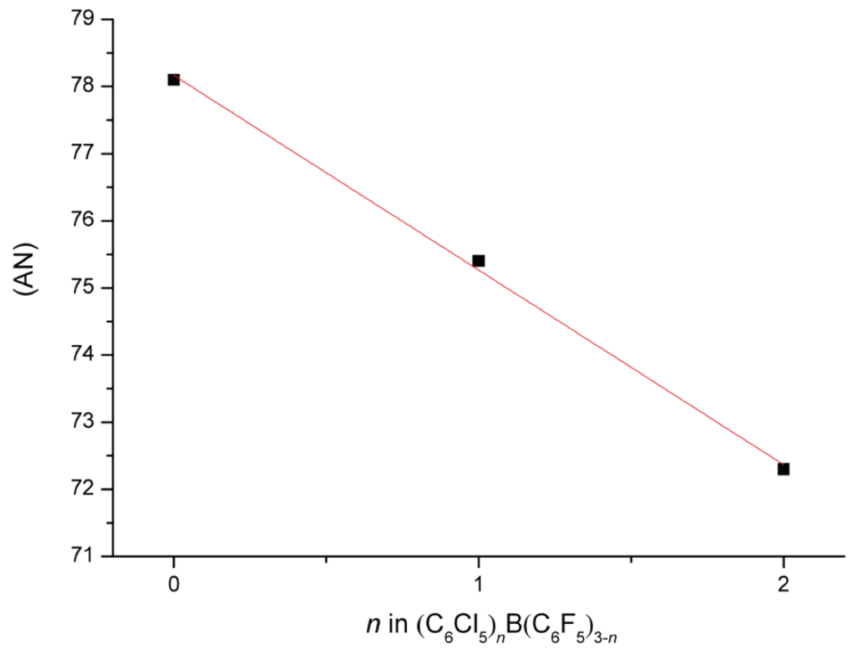

Figure 9. Plot of acceptor number (AN) vs $n$ in $\mathrm{B}\left(\mathrm{C}_{6} \mathrm{~F}_{5}\right)_{3-n}\left(\mathrm{C}_{6} \mathrm{Cl}_{5}\right)_{n}$ $(n=0-2)$.

phosphine oxide $\left(\mathrm{P}=\mathrm{O} 1.46(1) \AA \text { in } \mathrm{Ph}_{3} \mathrm{PO} \text {, for example }\right)^{41}$ at the locus of complexation. Thus, for $\mathrm{Et}_{3} \mathrm{PO}$ adduct formation is accomplishable for $n=0,1,2$ and a linear relationship exists throughout the series, whereas crotonaldehyde can only bind up to $n=1$; even here a decrease in Lewis acidity is evident from $\mathrm{B}\left(\mathrm{C}_{6} \mathrm{~F}_{5}\right)_{3}$. Despite the powerfully electron-withdrawing effects of three $\mathrm{C}_{6} \mathrm{Cl}_{5}$ ligands in $\mathbf{6}$, neither Lewis base can achieve coordination and the species may be considered to have passed the steric threshold in both circumstances.

Electrochemical Studies of $\mathrm{B}\left(\mathrm{C}_{6} \mathrm{~F}_{5}\right)_{3-n}\left(\mathrm{C}_{6} \mathrm{Cl}_{5}\right)_{n}(n=0-3)$. For a more absolute determination of electron density at the boron acceptor orbital, the reduction potentials for 3,5 and $\mathbf{6}$ are of interest. As shown by Power, reduction of $\mathrm{B}(\mathrm{Mes})_{3}$ and subsequent $\mathrm{X}$-ray structure determination of the resultant radical anion reveals that minimal structural reorganization of the trigonal planar environment of the borane occurs upon electron transfer; ${ }^{29}$ thus the potentials may be viewed as an approximate measure of the electrophilicity of $\mathrm{B}_{(}\left(\mathrm{C}_{6} \mathrm{~F}_{5}\right)_{3-n}\left(\mathrm{C}_{6} \mathrm{Cl}_{5}\right)_{n}(n=$ $0-3)$ in the absence of steric effects. In spite of the prevalent use of $\mathrm{B}\left(\mathrm{C}_{6} \mathrm{~F}_{5}\right)_{3}$ as a powerful Lewis acid no report exists to date that claims to directly observe the voltammetric reduction of this species, even though evidence documents its use as a one electron oxidant. ${ }^{42}$ Cummings et al. studied the cyclic voltammetry of the series $\mathrm{B}\left(\mathrm{C}_{6} \mathrm{~F}_{5}\right)_{3-n}(\text { Mes })_{n}(n=1-3)$ in order to estimate the redox potential of $\mathrm{B}\left(\mathrm{C}_{6} \mathrm{~F}_{5}\right)_{3}$ (THF, $0.1 \mathrm{M}\left[{ }^{n} \mathrm{Bu}_{4} \mathrm{~N}\right]\left[\mathrm{BF}_{4}\right]$ electrolyte) via extrapolation. ${ }^{43}$ Since these mesityl-substituted boranes are documented to only weakly coordinate THF (a moderately strong donor) it is plausible that the observation of a reduction wave for these species is due to high enough concentrations of the free threecoordinate tris(aryl)borane electron acceptors in solution. However, the $\mathrm{C}_{6} \mathrm{Cl}_{5}$ analogues are anticipated to be substantially more electron-deficient and indeed 3 strongly coordinates THF; examination of the reduction of this compound using $\mathrm{CV}$ under comparable conditions resulted in poorly defined voltammograms with no discernible waves. However, conducting experiments in the weakly coordinating solvent $\mathrm{CH}_{2} \mathrm{Cl}_{2}$ allowed the observation of well-defined cyclic voltammograms for all compounds, recorded at various scan rates $\left(50-500 \mathrm{mVs}^{-1}\right.$; Figure 11). A plot of the reductive peak current vs the square root of the voltage scan rate was constructed (Figure 11, insets) and in all cases a linear relationship was observed, confirming that the reduction was operating under diffusion control. ${ }^{44}$

When the potential was scanned initially in a negative direction a single reduction wave was observed at every scan rate for each complex. At lower scan rates (e.g., $50 \mathrm{mVs}^{-1}$ ) when the direction was subsequently reversed the corresponding oxidation waves were observed to be rather broad and smaller in height than the reduction wave. At higher scan rates the oxidative waves became more pronounced and the ratio of the oxidative to reductive peak current increased, but was always less than 1:1 even at scan rates of up to $10 \mathrm{~V} \mathrm{~s}^{-1}$. The observed cyclic voltammetric behavior is consistent with the reduction corresponding to an $\mathrm{EC}$ mechanism ${ }^{45}$ where "E" denotes a heterogeneous electron transfer step and "C" denotes a follow-up homogeneous chemical step, and is similar to the behavior observed by Cummings et al. for $\mathrm{B}\left(\mathrm{C}_{6} \mathrm{~F}_{5}\right)_{3-n}(\mathrm{Mes})_{n}$. Upon formation of the radical anion of the parent complex, the radical anion rapidly undergoes further homogeneous follow-up chemistry leading to decomposition of the radical anion produced at the electrode. At slow scan rates the decomposition of the intermediate radical anion is sufficiently fast compared to the voltammetric time scale so that its corresponding reoxidation is not observed. As the scan rate is increased the kinetics of decomposition begin to be outrun and a correspondingly larger oxidation wave is then observed until the ratio of $i_{\mathrm{pOx}} / i_{\mathrm{pRed}}$ approaches unity. The formal reduction potential of each compound 3, 5 and $\mathbf{6}$ is calculated using the midpeak potential, $E_{\text {mid }}=\left(E_{\mathrm{pOx}}+E_{\mathrm{pRed}}\right) / 2$, and are listed in Table 7. A clear trend is observable whereby the reduction peak potential of each complex was found to shift to increasingly less negative potentials, and the voltammetry appears to become more reversible as the number of $\mathrm{C}_{6} \mathrm{Cl}_{5}$ substituents attached to the boron center increases. These findings support the NMR spectral data that a $\mathrm{C}_{6} \mathrm{Cl}_{5}$ group is more electron-withdrawing than a $\mathrm{C}_{6} \mathrm{~F}_{5}$ substituent, thus rendering the boron center more 


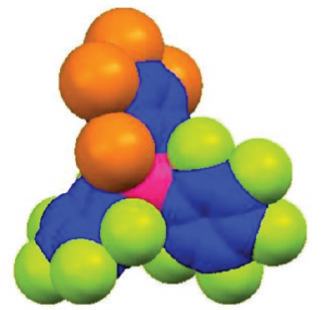

(a)

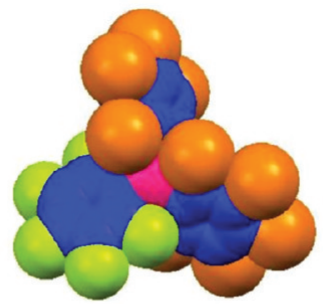

(b)

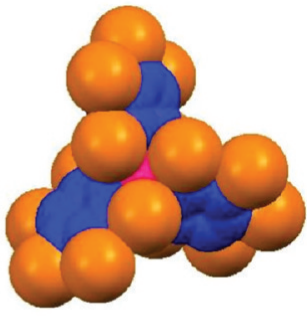

(c)

Figure 10. Space-fill diagram of (a) 3, (b) 5 and (c) 6; $\mathrm{C}$ atoms blue, $\mathrm{Cl}$ atoms orange, $\mathrm{F}$ atoms green, and $\mathrm{B}$ atoms pink.
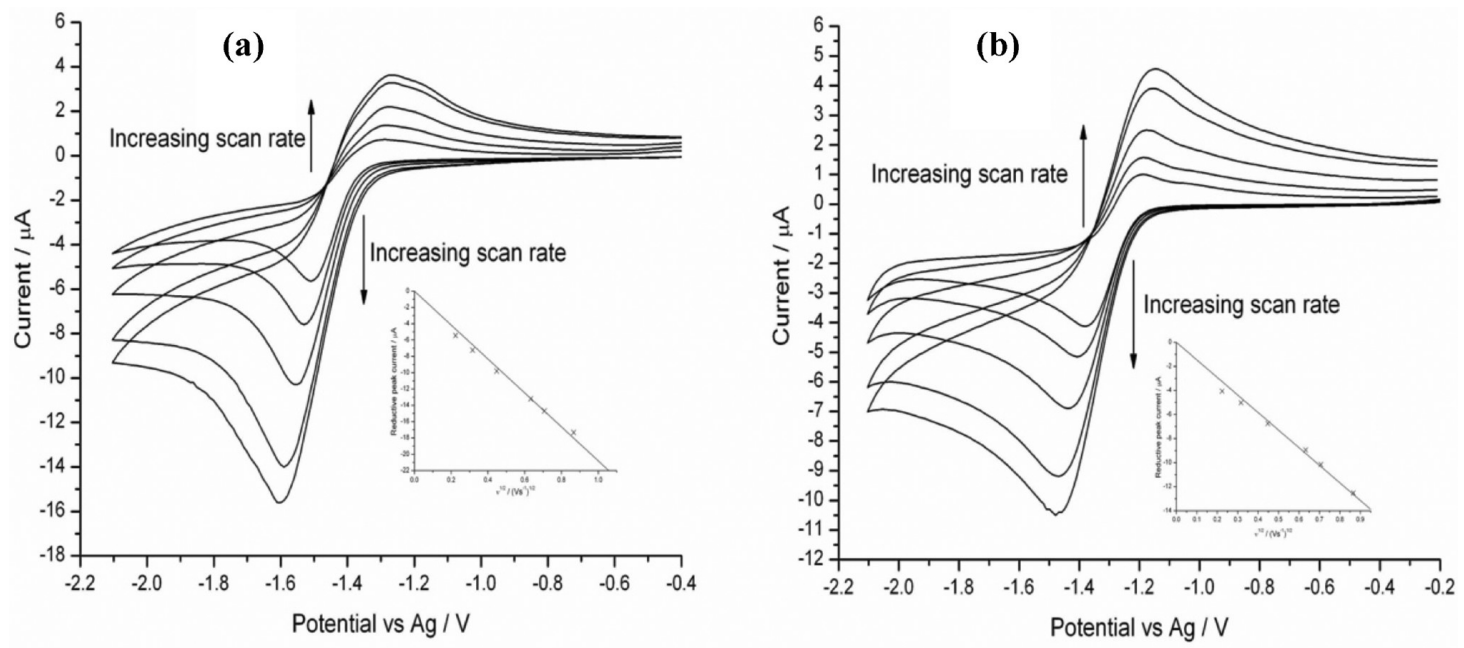

(c)

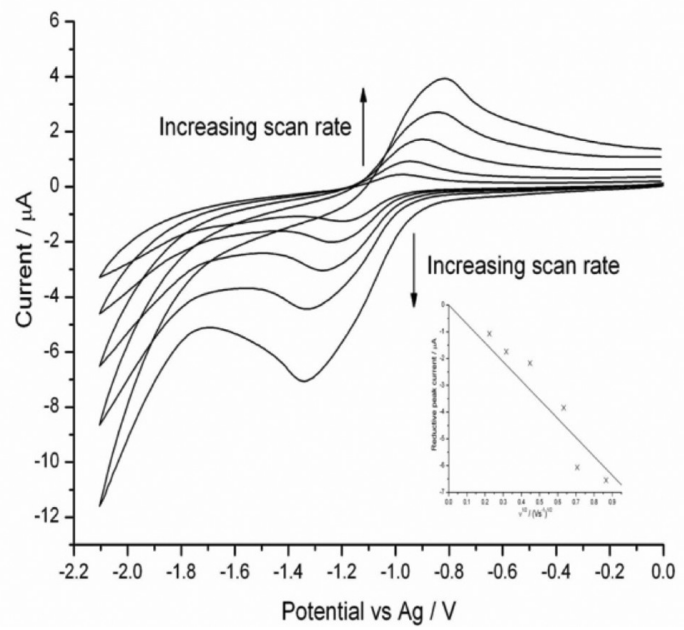

Figure 11. Overlaid cyclic voltammograms recorded at scan rates of 50 to $500 \mathrm{mVs}^{-1}$ in $\mathrm{CH}_{2} \mathrm{Cl}_{2}\left(0.1 \mathrm{M}\left[{ }^{n} \mathrm{Bu}_{4} \mathrm{~N}\right]\left[\mathrm{BF}_{4}\right]\right)$ of (a) $3(10 \mathrm{mM}$ concentration); (b) 5 (10 mM concentration); (c) 6 (5 mM concentration). (Insets) Respective plots of reductive peak current vs square-root of voltage scan rate.

oxidizing and correlates well with the more positive Hammett parameter for aryl-bound $\mathrm{Cl}$ vs $\mathrm{F}$. In addition, the larger size of $\mathrm{Cl}$ (especially in the ortho position) induces an increased shielding of the boron-centerd radical anion upon reduction, inhibiting bimolecular decomposition pathways and hence increasing the stability/reversibility of the voltammetry; a similar buttressing effect is attributed to the stability, and hence persistence, of the isoelectronic $\left[\mathrm{C}\left(\mathrm{C}_{6} \mathrm{Cl}_{5}\right)_{3}\right]^{\bullet}{ }^{46}$ Assuming a linear relationship between these potentials and the number of $\mathrm{C}_{6} \mathrm{Cl}_{5}$ substituents attached to each boron center provides an estimate of the reduction potential for $\mathrm{B}\left(\mathrm{C}_{6} \mathrm{~F}_{5}\right)_{3}$ of $-1.92 \mathrm{~V} \pm 0.1 \mathrm{~V}$ (vs $\mathrm{Cp}_{2} \mathrm{Fe}^{0 /+}$ ).

Previous attempts to observe the direct reduction of $\mathrm{B}\left(\mathrm{C}_{6} \mathrm{~F}_{5}\right)_{3}$ have employed either $\mathrm{CH}_{2} \mathrm{Cl}_{2}$ or THF solvent (despite the fact that $\mathrm{THF} \cdot \mathrm{B}\left(\mathrm{C}_{6} \mathrm{~F}_{5}\right)_{3}$ is known to be a strongly bound adduct $)^{47}$ and commonly used electrolytes such as $\left[{ }^{n} \mathrm{Bu}_{4} \mathrm{~N}\right]\left[\mathrm{ClO}_{4}\right]$ or 
Table 7. Average values of $E_{\text {mid }}$ measured from $\mathrm{CV}$ data for complexes $\mathrm{B}\left(\mathrm{C}_{6} \mathrm{~F}_{5}\right)_{3-n}\left(\mathrm{C}_{6} \mathrm{Cl}_{5}\right)_{n}(n=0-3)$

$\begin{array}{cc}\mathrm{B}\left(\mathrm{C}_{6} \mathrm{~F}_{5}\right)_{3-n}\left(\mathrm{C}_{6} \mathrm{Cl}_{5}\right)_{n} & E_{\text {mid }} / \mathrm{V}^{a} \\ \mathrm{~B}\left(\mathrm{C}_{6} \mathrm{~F}_{5}\right)_{3} & -1.97 \pm 0.10 \\ \mathbf{3} & -1.87 \pm 0.05 \\ \mathbf{5} & -1.55 \pm 0.05 \\ \mathbf{6} & -1.48 \pm 0.02\end{array}$

${ }^{a}$ Potentials are reported vs $\mathrm{Cp}_{2} \mathrm{Fe}^{0 /+}\left(\mathrm{CH}_{2} \mathrm{Cl}_{2}\right)$ at a $\mathrm{Pt}$ macrodisc electrode.

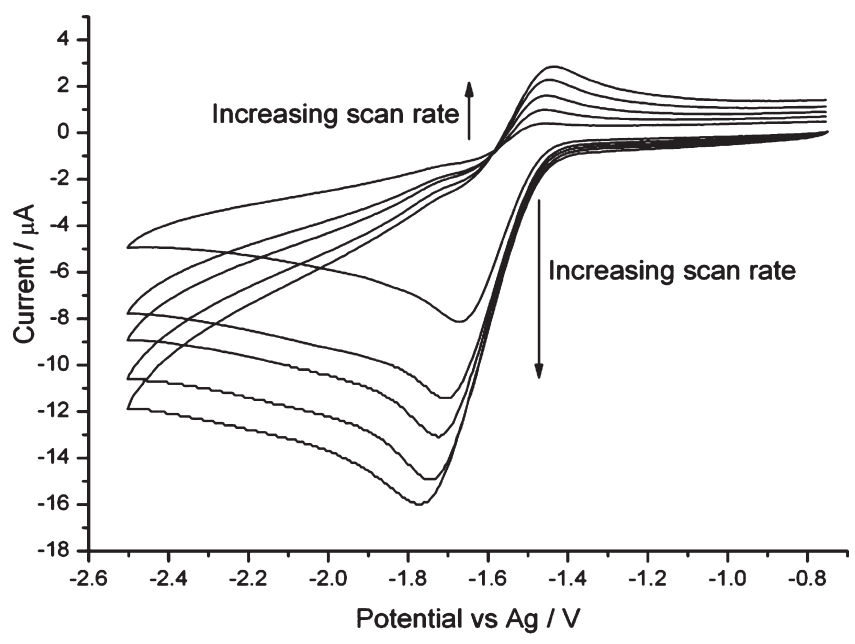

Figure 12. Overlaid cyclic voltammograms of $\mathrm{B}\left(\mathrm{C}_{6} \mathrm{~F}_{5}\right)_{3}$ in $\mathrm{CH}_{2} \mathrm{Cl}_{2}$ (5 mM, 0.1 M $\left[{ }^{n} \mathrm{Bu}_{4} \mathrm{~N}\right]\left[\mathrm{BArF}_{24}\right] ; 1-5 \mathrm{~V} \mathrm{~s}^{-1}$ scan rate).

$\left[{ }^{n} \mathrm{Bu}_{4} \mathrm{~N}\right]\left[\mathrm{BF}_{4}\right]$; at best, ill-defined curves were observed. ${ }^{42,43}$ $\mathrm{B}\left(\mathrm{C}_{6} \mathrm{~F}_{5}\right)_{3}$ has demonstrated a rich oxo-anion binding chemistry which quite possibly extends to $\mathrm{ClO}_{4}{ }^{-}$(reported to be more coordinating than $\left.\mathrm{BF}_{4}{ }^{-}\right),{ }^{48}$ and since the Lewis acidity of this borane has been judged to be similar to that of $\mathrm{BF}_{3}$, it is probable that $\mathrm{F}^{-}$abstraction from $\mathrm{BF}_{4}{ }^{-}$to form $\left[\mathrm{FB}\left(\mathrm{C}_{6} \mathrm{~F}_{5}\right)_{3}\right]^{-}$occurs; ${ }^{49}$ in both of these examples, the supporting electrolyte would quench the acceptor orbital and hence inhibit reduction. With these potential pitfalls in mind we resorted to the $\left[{ }^{n} \mathrm{Bu}_{4} \mathrm{~N}\right]^{+}$salt of the weakly coordinating anion $\left[\mathrm{BArF}_{24}\right]^{-}$in $\mathrm{CH}_{2} \mathrm{Cl}_{2}$ as electrolyte $\left(\mathrm{BArF}_{24}=\mathrm{B}\left[3,5-\left(\mathrm{CF}_{3}\right)_{2} \mathrm{C}_{6} \mathrm{H}_{3}\right]_{4}\right)$; Figure 12 shows the resulting cyclic voltammetry of $\mathrm{B}\left(\mathrm{C}_{6} \mathrm{~F}_{5}\right)_{3}$, obtained successfully for the first time. At modest scan rates $\left(<1 \mathrm{~V} \mathrm{~s}^{-1}\right)$, a reduction wave is observed which corresponds to a one-electron reduction forming the $\left[\mathrm{B}\left(\mathrm{C}_{6} \mathrm{~F}_{5}\right)_{3}\right]^{\bullet-}$ radical anion, at $-1.97 \pm$ $0.1 \mathrm{~V}$. The rate of decomposition of $\mathrm{B}\left(\mathrm{C}_{6} \mathrm{~F}_{5}\right)_{3}$ continues the trend observed for $\mathrm{B}\left(\mathrm{C}_{6} \mathrm{~F}_{5}\right)_{3-n}\left(\mathrm{C}_{6} \mathrm{Cl}_{5}\right)_{n}$ complexes $(n=1-3)$ and is the fastest of the series, such that a back peak corresponding to the reoxidation of the radical anion is only observed at scan rates in excess of $1 \mathrm{~V} \mathrm{~s}^{-1}$.

Figure 13 consolidates the measured $E_{\text {mid }}$ potentials of all complexes $\mathrm{B}\left(\mathrm{C}_{6} \mathrm{~F}_{5}\right)_{3-n}\left(\mathrm{C}_{6} \mathrm{Cl}_{5}\right)_{n}$ complexes $(n=0-3)$ vs the number of $\mathrm{C}_{6} \mathrm{Cl}_{5}$ groups in the molecule; a clear linear trend is observed and the estimated value of the reduction potential of $\mathrm{B}\left(\mathrm{C}_{6} \mathrm{~F}_{5}\right)_{3}$ is indeed very close to the measured value. It is also interesting to compare the estimated values from the $\mathrm{B}\left(\mathrm{C}_{6} \mathrm{~F}_{5}\right)_{3-n^{-}}$ (Mes $)_{n}$ series used by Cummings et al. to estimate the potential of $\mathrm{B}\left(\mathrm{C}_{6} \mathrm{~F}_{5}\right)_{3}$ and to compare their estimate with our measured value. ${ }^{43}$ To do this, we have followed the IUPAC convention of

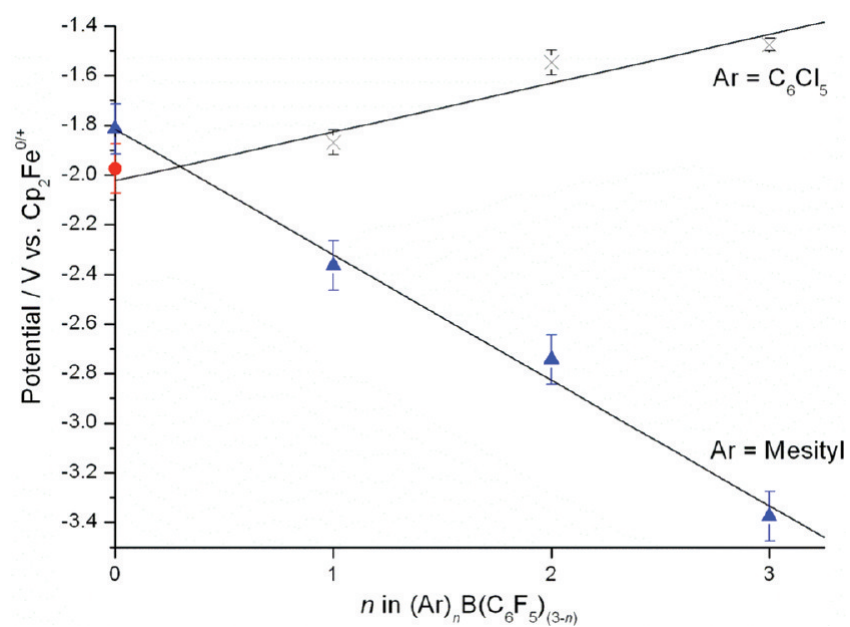

Figure 13. A plot showing the $E_{\text {mid }}$ potentials of complexes B$\left(\mathrm{C}_{6} \mathrm{~F}_{5}\right)_{3-n}\left(\mathrm{C}_{6} \mathrm{Cl}_{5}\right)_{n}(n=0-3$; denoted $\times)$ vs the number of substituent $\mathrm{C}_{6} \mathrm{Cl}_{5}$ groups in the complex, and also the $E_{\text {mid }}$ values determined for the series $\mathrm{B}\left(\mathrm{C}_{6} \mathrm{~F}_{5}\right)_{3-n}(\mathrm{Mes})_{n}(n=0-3)$ and their estimated value for the reduction potential of $\mathrm{B}\left(\mathrm{C}_{6} \mathrm{~F}_{5}\right)_{3}$ (blue $\left.\boldsymbol{\Delta}\right){ }^{43}$ The measured potential, $E_{\text {mid }}$, for $\mathrm{B}\left(\mathrm{C}_{6} \mathrm{~F}_{5}\right)_{3}$ in $\mathrm{CH}_{2} \mathrm{Cl}_{2}$ (red $\bullet$ ), has also been included.

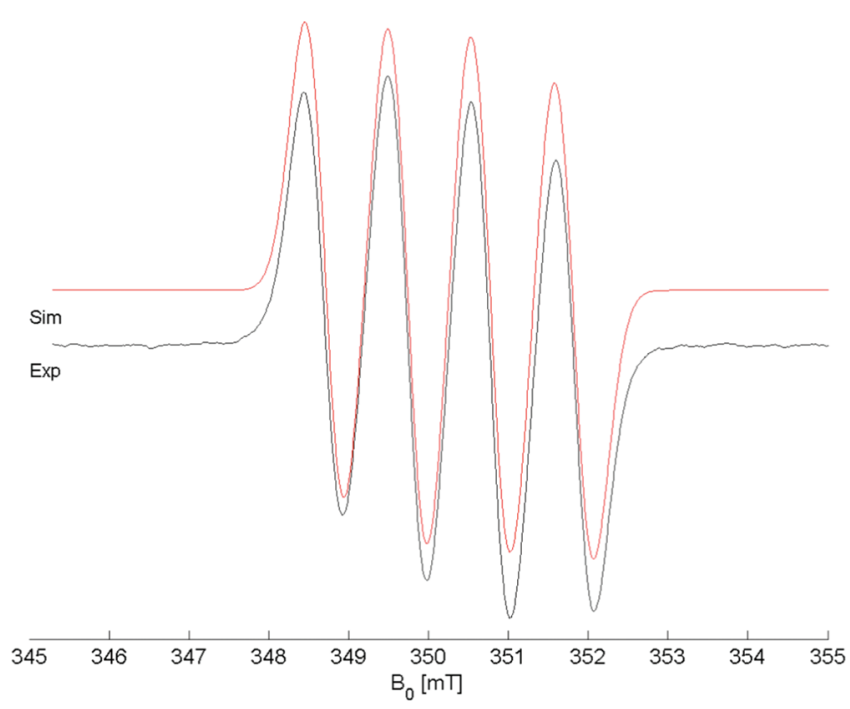

Figure 14. Experimental (black) and simulated (red; isotropic linewidth $6.1 \mathrm{G}) \mathrm{X}$-band EPR spectra of [3] ${ }^{\circ-}$ in THF at $298 \mathrm{~K}\left({ }^{11} \mathrm{~B} 80.1 \%\right.$, $\left.I=3 / 2 ;{ }^{10} \mathrm{~B} 19.9 \%, I=3\right)$.

referencing nonaqueous potentials to the $\mathrm{Cp}_{2} \mathrm{Fe}^{\mathrm{O} /+}$ couple in the solvent system of choice rather than the practice of referencing potentials to the aqueous SCE reference electrode. ${ }^{50}$ The data show that the estimated reduction potential of $\mathrm{B}\left(\mathrm{C}_{6} \mathrm{~F}_{5}\right)_{3}$ in the work of Cummings et al. is also reassuringly close to our measured value; the difference in values may be accounted for by recognizing that the studies have been conducted in different solvents $\left(\mathrm{CH}_{2} \mathrm{Cl}_{2}\right.$ and THF $)$. The difference in shift of ca. +200 $\mathrm{mV}$ per $\mathrm{C}_{6} \mathrm{Cl}_{5}$ introduced compared with ca. $-500 \mathrm{mV}$ obtained for the mesityl series may be understood in that for the former case $\mathrm{C}_{6} \mathrm{~F}_{5}$ (a $\sigma$-acid and $\pi$-donor) is replaced by a group of slightly greater electron-withdrawing ability (predominantly $\sigma$ acid) whereas in the latter it is replaced by a strongly electrondonating ligand (a $\sigma$-donor); the effect on the electrode potentials is therefore appreciably greater. 
EPR Study of $\left[\mathrm{B}\left(\mathrm{C}_{6} \mathrm{Cl}_{5}\right)_{3}\right]^{\bullet-}$. The radical anion $\left[\mathrm{B}\left(\mathrm{C}_{6} \mathrm{~F}_{5}\right)_{3}\right]^{\bullet-}$ has been previously reported via reduction of the parent Lewis acid with $\mathrm{Cp}^{*}{ }_{2} \mathrm{Co}$ in $\mathrm{THF}$ at $-50{ }^{\circ} \mathrm{C}$; the EPR spectrum was rapidly recorded at this temperature due to the transient nature of the anion $\left(t_{1 / 2} \approx 2 \mathrm{~min}, 298 \mathrm{~K}\right)$. $^{51}$ Electrochemical experiments suggest the reduction product of $\mathrm{B}\left(\mathrm{C}_{6} \mathrm{Cl}_{5}\right)_{3}$ to be considerably more stable, and accordingly the synthesis of $\left[\mathrm{B}\left(\mathrm{C}_{6} \mathrm{Cl}_{5}\right)_{3}\right]^{\bullet-}$ was investigated. Reduction of $\mathbf{6}$ using $\mathrm{Na}(\mathrm{s})$ in THF was conducted at room temperature, resulting in a vivid blue solution whereupon the EPR spectrum was obtained. Figure 14 shows the experimental observations and simulated spectrum, which confidently support the existence of $[6]^{\bullet-}$; furthermore, the multiplicity of the EPR signal precludes dimeric association of the radicals in solution.

The value of hyperfine coupling $a\left({ }^{11} \mathrm{~B}\right)(10.3 \mathrm{G})$ agrees very well with those reported for the tris(aryl)borane radical anions $\left[\mathrm{B}\left(\mathrm{C}_{6} \mathrm{~F}_{5}\right)_{3}\right]^{\bullet-}(10.5 \mathrm{G}),\left[\mathrm{B}(\mathrm{Mes})_{3}\right]^{\bullet-}(10.3 \mathrm{G})$ and $\left[\mathrm{BPh}_{3}\right]^{\bullet-}$ $(9.8 \mathrm{G})$, and $g(2.002)$ is very close to the free electron value $\left(g_{\mathrm{e}}=\right.$ 2.0023). Measurements of the exponential decay in the EPR signal intensity gave a half-life of $115 \mathrm{~min}$ at $298 \mathrm{~K}$ revealing $[6]^{\bullet-}$ to be considerably more stable than its perfluoro analogue. $^{51}$

\section{- CONCLUSIONS}

The complete series of perchloroaryl Lewis Acids B$\left(\mathrm{C}_{6} \mathrm{~F}_{5}\right)_{3-n}\left(\mathrm{C}_{6} \mathrm{Cl}_{5}\right)_{n}(n=1-3 ; 3,5$ and 6$)$ have been successfully synthesized and comprehensively characterized; perchlorination of all the aryl substituents confers considerable thermal and hydrolytic stability to 6 . The solid-state structures reveal a trigonal planar environment for boron in all the compounds, despite the asymmetry of the ligand set in the complexes $\mathbf{3}$ and $\mathbf{5}$. Solution ${ }^{19} \mathrm{~F},{ }^{13} \mathrm{C}$ and ${ }^{11} \mathrm{~B}$ NMR studies reveal a trend of $\mathrm{B}-\mathrm{C}_{6} \mathrm{~F}_{5}$ resonance interactions being replaced by primarily inductive effects arising from increasing $\mathrm{C}_{6} \mathrm{Cl}_{5}$ incorporation. A decrease in Lewis acidity has been established upon sequential substitution of $\mathrm{C}_{6} \mathrm{~F}_{5}$ with $\mathrm{C}_{6} \mathrm{Cl}_{5}$ in $\mathrm{B}\left(\mathrm{C}_{6} \mathrm{~F}_{5}\right)_{3}$ for $n=0-2$, as demonstrated by the Gutmann-Beckett method, whereas the Childs method was only successful for $n=0$ and 1 ; the acceptor properties of 6 could not be determined by either of these techniques. Conversely, electrochemical studies show that the boron center becomes more electron deficient (oxidizing) as the series is traversed, demonstrating a $\mathrm{C}_{6} \mathrm{Cl}_{5}$ substituent to be more electron withdrawing than $\mathrm{C}_{6} \mathrm{~F}_{5}$. The optimized structures of all the Lewis acids, $\mathrm{B}\left(\mathrm{C}_{6} \mathrm{~F}_{5}\right)_{3-n}\left(\mathrm{C}_{6} \mathrm{Cl}_{5}\right)_{n}(n=0-3)$, using density functional theory (B3LYP/TZVP) are all fully consistent with the experimental structural data. Computed ${ }^{11} \mathrm{~B}$ shielding constants also replicate the experimental trend almost quantitatively, and the computed natural charges on the boron center increase in the order $n=0(0.81)<n=1(0.89)<n=2(1.02)<n=3$ (1.16), supporting the hypothesis that electrophilicity increases concomitantly with substitution of $\mathrm{C}_{6} \mathrm{~F}_{5}$ for $\mathrm{C}_{6} \mathrm{Cl}_{5}$. All the results may be coherently rationalized be realizing that various measurements of Lewis acidity may be dominated by either steric and/or electronic effects. While electrochemistry provides a physiochemical measure of the electron affinity of the $B$ center in these compounds, it neglects the steric cost of $\mathrm{B} s p^{2}-s p^{3}$ rehybridization, which is important for bulky boranes upon coordination of Lewis bases. However, the Gutmann-Beckett/Childs' methods incorporate both factors in their measurement and give a more reliable indication of "chemical" Lewis acidity. The reactivity of these new boranes, particularly as Frustrated Lewis Pair partners in the presence of $\mathrm{H}_{2}$, are the subject of current investigation and will be reported in due course.

\section{EXPERIMENTAL DETAILS}

General. All reactions and compounds were manipulated under $\mathrm{N}_{2}$ using either an MBraun Unilab glovebox or using standard Schlenk line techniques on a dual manifold vacuum/inert gas line, unless stated otherwise. For the manipulation of moisture sensitive compounds, all glassware was heated to $170{ }^{\circ} \mathrm{C}$ before use. Solvents and solutions were transferred using a positive pressure of nitrogen through stainless steel or Teflon cannulae or via plastic syringes for volumes less than $20 \mathrm{~mL}$. Filtrations were performed using either glassware containing sintered glass frits or modified stainless steel cannulae fitted with glass microfiber filters. Pentane, hexane, toluene and $\mathrm{CH}_{2} \mathrm{Cl}_{2}$ were dried using an MBraun SPS- 800 solvent purification system, whereas $\mathrm{Et}_{2} \mathrm{O}$ was distilled from purple $\mathrm{Na}$ /benzophenone diketyl; all except $\mathrm{CH}_{2} \mathrm{Cl}_{2}$ were stored over K-mirrored ampules. Deuterated NMR solvents were dried and freeze-thaw degassed over the appropriate drying agent: $\mathrm{C}_{6} \mathrm{D}_{6}, \mathrm{C}_{7} \mathrm{D}_{8}$ (K); $\mathrm{CD}_{2} \mathrm{Cl}_{2}$ (activated $3 \AA$ molecular sieves) and purchased from Goss Scientific (99.6, 99.6 and $99.8 \% \mathrm{D}$ respectively). $\mathrm{BBr}_{3}$ (99.9\%), $\mathrm{BCl}_{3}$ (1.0 M in heptane), $\mathrm{C}_{6} \mathrm{Cl}_{6}$ (99.9\%), ${ }^{n} \mathrm{BuLi}$ (2.5 $\mathrm{M}$ in hexanes), 2,2,6,6tetramethylpiperidine $(>99 \%)$, trans-crotonaldehyde $(>99 \%)$ and $\left[{ }^{n} \mathrm{Bu}_{4} \mathrm{~N}\right]\left[\mathrm{BF}_{4}\right]$ were purchased from Sigma Aldrich; all were used as received. $\left.\mathrm{CuC}_{6} \mathrm{~F}_{5},{ }^{52}{ }^{n} \mathrm{Bu}_{4} \mathrm{~N}\right]\left[\mathrm{B}\left(\mathrm{C}_{6} \mathrm{H}_{3}\left(\mathrm{CF}_{3}\right)_{2}\right)_{4}\right]$ and $\mathrm{B}\left(\mathrm{C}_{6} \mathrm{~F}_{5}\right)_{3}$ were prepared according to literature procedures. NMR spectra were recorded on a $300 \mathrm{MHz}$ Varian VX-Works spectrometer. ${ }^{1} \mathrm{H}$ and ${ }^{13} \mathrm{C}$ chemical shifts are given relative to $\mathrm{Me}_{4} \mathrm{Si}$ and referenced internally to the residual proton shift in the deuterated solvent employed. ${ }^{11} \mathrm{~B},{ }^{19} \mathrm{~F}$ and ${ }^{31} \mathrm{P}$ chemical shifts were referenced externally to $\mathrm{BF}_{3} \cdot \mathrm{OEt}_{2}, \mathrm{CFCl}_{3}$ and $85 \% \mathrm{H}_{3} \mathrm{PO}_{4}$. Assessment of Lewis acidity using the GutmannBeckett method ${ }^{12}$ followed a modification described by D.W. Stephan et al. ${ }^{37 a}$ which used an excess of Lewis acid to $\mathrm{Et}_{3} \mathrm{PO}(3: 1)$, dissolved in $\mathrm{CD}_{2} \mathrm{Cl}_{2}$. To accurately record $\Delta \delta$, the solution was placed in an NMR tube along with a sealed reference capillary containing uncoordinated phosphine oxide. The ${ }^{31} \mathrm{P}$ NMR shifts were recorded at $298 \mathrm{~K}$. For the Childs Method was performed as described by Childs et al. ${ }^{36 a}$ Lewis acid and trans-crotonaldehyde were mixed in a 1:1 ratio and placed in an NMR tube. The ${ }^{1} \mathrm{H}$ NMR chemical shift of the $\mathrm{H}_{3}$ proton of crotonaldehyde was then recorded. High resolution mass spectrometry samples (HRMS; EI) were recorded using a Bruker FT-ICR-MS Apex III spectrometer and IR spectra were recorded on a Nicolet MAGNA-IR 560 FT-IR spectrometer (range $4000-400 \mathrm{~cm}^{-1}$, resolution $0.5 \mathrm{~cm}^{-1}$ ). Crystals suitable for X-ray diffraction were mounted on a glass fiber either bare, or using perfluoropolyether oil, and mounted in a stream of $\mathrm{N}_{2}$ at $150 \mathrm{~K}$ using an Oxford Cryosystems Cryostream unit. ${ }^{53}$ Diffraction data were obtained using graphite monochromated Mo $\mathrm{K}_{\alpha}$ radiation on an Nonius KappaCCD diffractomer, and processed using the DENZO-SMN package. ${ }^{54}$ The structure was then solved using the direct methods program SIR92, ${ }^{55}$ which located all the non-hydrogen atoms. Subsequent full-matrix least-squares refinement was carried out using the CRYSTALS program suite. ${ }^{56}$ Full details are in the Supporting Information (CIF); crystallographic data (excluding structure factors) for 3, 5 and 6 have been deposited with the Cambridge Crystallographic Data Centre and can be obtained via www. ccdc.cam.ac.uk/data_request/cif. Electrochemical experiments were performed using an Autolab PGSTAT 30 computer-controlled potentiostat. Cyclic voltammetry (CV) was performed using a three-electrode configuration consisting of a Pt disk working electrode (GoodFellow, Cambridge, UK 99.99\% area $1.7 \pm 0.3 \times 10^{-3} \mathrm{~cm}^{2}$ ), a Pt gauze counter electrode and a Ag wire pseudoreference electrode. Pt working electrodes were polished between experiments using successive grades of alumina slurries from 1.0 to $0.3 \mu \mathrm{m}$ rinsed in distilled water and subjected to brief ultrasonication to remove any adhered alumina microparticles. The electrodes were 
then dried in an oven at $120^{\circ} \mathrm{C}$ to remove any residual traces of water. For either cell arrangement the potentials of the Ag wire pseudoreference electrodes were found to drift by as much as $100 \mathrm{mV}$ between experimental runs and therefore calibrated to the ferrocene/ferrocenium couple in $\mathrm{CH}_{2} \mathrm{Cl}_{2}$ in the absence of any borane complexes at the end of each run. All electrochemical measurements were performed at ambient temperatures under an inert $\mathrm{N}_{2}$ atmosphere containing either $0.1 \mathrm{M}$ $\left[{ }^{n} \mathrm{Bu}_{4} \mathrm{~N}\right]\left[\mathrm{BF}_{4}\right]$ or $0.1 \mathrm{M}\left[{ }^{n} \mathrm{Bu}_{4} \mathrm{~N}\right]\left[\mathrm{B}\left(\mathrm{C}_{6} \mathrm{H}_{3}\left(\mathrm{CF}_{3}\right)_{2}\right)_{4}\right]$ in $\mathrm{CH}_{2} \mathrm{Cl}_{2}$.

Computational Details. Calculations were performed at the DFT level with the B3LYP functional ${ }^{57}$ and the TZVP basis set ${ }^{58}$ of Ahlrichs and co-workers, as implemented in Gaussian03. ${ }^{59}$ The structures of stationary points were fully optimized without any symmetry constraints and confirmed to be minima by the absence of imaginary frequencies. Where crystallographic data were available, the experimental coordinates were used as the initial guess for the structure. ${ }^{11} \mathrm{~B}$ NMR shielding constants were calculated with the Gauge-Independent Atomic Orbital (GIAO) method, ${ }^{60}$ using the geometries obtained at the B3LYP/TZVP level. These calculations employed the B3LYP functional in conjunction with a polarizable continuum model (PCM) ${ }^{61}$ using dichloromethane $(\varepsilon=8.93)$ as the solvent. The TZVP basis set on boron was replaced by a basis set optimized for shielding constants, aug-pcS-2(triple- $\zeta$ quality), ${ }^{62}$ while the TZVP basis set was retained for the other atoms $(\mathrm{C}, \mathrm{F}, \mathrm{Cl})$. Relative chemical shifts $\left(\delta_{\text {calc }}\right)$ were obtained by referencing the isotropic nuclear magnetic shielding constant of the probe atom $\left(\sigma_{\mathrm{X}}\right)$ against the shielding constant $\left(\sigma_{\text {ref }}\right)$ of the $\mathrm{B}$ atom in $\mathrm{B}\left(\mathrm{C}_{6} \mathrm{~F}_{5}\right)_{3}$ with $\delta_{\text {ref }}$ $\left({ }^{11} \mathrm{~B}\right.$ NMR $)=61.2 \mathrm{ppm}$, thus $\delta_{\text {calc }}=\sigma_{\text {ref }}-\sigma_{\mathrm{X}}+\delta_{\text {ref. }}$.

$\mathrm{C}_{6} \mathrm{Cl}_{5} \mathrm{Li}$. This is adapted from a literature procedure. ${ }^{18}$ A $500 \mathrm{~mL}$ Schlenk was charged under a nitrogen flush with $\mathrm{C}_{6} \mathrm{Cl}_{6}(5.70 \mathrm{~g}, 20$ $\mathrm{mmol}$ ) and left under vacuum for $20 \mathrm{~min}$ to remove any moisture. Following the addition of $150 \mathrm{~mL} \mathrm{Et}_{2} \mathrm{O}$, the slurry was cooled to $-78^{\circ} \mathrm{C}$ using a $\mathrm{CO}_{2(\mathrm{~s})}$ /acetone bath. With rapid stirring ${ }^{n} \mathrm{BuLi}$ (18.2 mL, 20.4 $\mathrm{mmol}, 2.5 \mathrm{M}$ in hexanes) in hexane was added by means of a syringe. The contents were allowed to warm to $-10{ }^{\circ} \mathrm{C}$ until solid $\mathrm{C}_{6} \mathrm{Cl}_{6}$ was no longer visible, and a translucent amber solution of $\mathrm{C}_{6} \mathrm{Cl}_{5} \mathrm{Li}$ had formed. The contents were later cooled to $-78^{\circ} \mathrm{C}$.

$\mathrm{Zn}\left(\mathrm{C}_{6} \mathrm{Cl}_{5}\right)_{2}(1) \cdot \mathrm{C}_{6} \mathrm{Cl}_{5} \mathrm{Li}$ (from $28 \mathrm{mmol} \mathrm{C}_{6} \mathrm{Cl}_{6}$ ) in $\mathrm{Et}_{2} \mathrm{O}$ at $-78^{\circ} \mathrm{C}$ was rapidly transferred via cannula to a stirred $\mathrm{Et}_{2} \mathrm{O}(100 \mathrm{~mL})$ solution of $\mathrm{ZnCl}_{2}$ (1.91 g, $14 \mathrm{mmol}$ ) at $-20^{\circ} \mathrm{C}$. The yellow reaction mixture was then slowly warmed to room temperature over the course of $3 \mathrm{~h}$ whereupon a precipitate began to form, which was stirred for a further $12 \mathrm{~h}$. Filtration through Celite to remove $\mathrm{LiCl}$, washing with $\mathrm{Et}_{2} \mathrm{O}(2 \times$ $50 \mathrm{~mL}$ ), and subsequent removal of the solvent under reduced pressure produced a pale yellow solid, which was washed with cold $\left(-78{ }^{\circ} \mathrm{C}\right)$ $\mathrm{Et}_{2} \mathrm{O}(2 \times 50 \mathrm{~mL})$ until the washings became colorless. Drying in vacuo for $12 \mathrm{~h}$ while slowly heating to $60^{\circ} \mathrm{C}$ afforded base-free $\mathrm{Zn}\left(\mathrm{C}_{6} \mathrm{Cl}_{5}\right)_{2}(\mathbf{1})$ as a white powder $(6.51 \mathrm{~g}, 82 \%, 11.5 \mathrm{mmol})$. HRMS (EI, $\mathrm{m} / z)$ : for $\mathrm{ZnC}_{12} \mathrm{Cl}_{10}$ Calcd: 557.6177. Found: 557.6163. IR (Nujol, $\mathrm{cm}^{-1}$ ): 1700 (m), $1653(\mathrm{~m}), 1559(\mathrm{~m}), 1533(\mathrm{~m}), 1465(\mathrm{~m}), 1334(\mathrm{~s}), 1311(\mathrm{~s}), 1230$ (m), $1128(\mathrm{~m}), 982$ (s), 659 (s), 524 (w). Anal. Calcd. for $\mathrm{ZnC}_{12} \mathrm{Cl}_{10}$ : C 25.55. Found: C 25.43.

$\mathrm{B}\left(\mathrm{C}_{6} \mathrm{Cl}_{5}\right) \mathrm{Br}_{2}$ (2). A $250 \mathrm{~mL}$ greaseless ampule was charged with a magnetic stirrer bar, $\mathrm{Zn}\left(\mathrm{C}_{6} \mathrm{Cl}_{5}\right)_{2}(6.51 \mathrm{~g}, 11.5 \mathrm{mmol})$, toluene $(150 \mathrm{~mL})$, and finally $\mathrm{BBr}_{3}(7.20 \mathrm{~g}, 2.77 \mathrm{~mL}, 28.8 \mathrm{mmol})$, before being sealed and heated $\left(100{ }^{\circ} \mathrm{C}\right)$ with stirring for $12 \mathrm{~h}$. The suspension was then cooled to room temperature and filtered through Celite, before stripping the solvent under vacuum to produce a solid. Washing this residue with pentane $(2 \times 50 \mathrm{~mL})$ gave $\mathrm{B}\left(\mathrm{C}_{6} \mathrm{Cl}_{5}\right) \mathrm{Br}_{2}(2)$ as an off-white powder (6.78 g, 70\%, $16.1 \mathrm{mmol}) .{ }^{13} \mathrm{C}\left\{{ }^{1} \mathrm{H}\right\} \operatorname{NMR}\left(\mathrm{CD}_{2} \mathrm{Cl}_{2}, 75 \mathrm{MHz}\right)$ : $\delta 135.6\left(\mathrm{~s}\right.$, para- $\left.\mathrm{C}_{6} \mathrm{Cl}_{5}\right) ; \delta 132.8,130.0$ (s, meta- $\mathrm{C}_{6} \mathrm{Cl}_{5}$ and ortho- $\left.\mathrm{C}_{6} \mathrm{Cl}_{5}\right)$. Resonance for ipso- $\mathrm{C}_{6} \mathrm{Cl}_{5}$ not observed. ${ }^{11} \mathrm{~B} \mathrm{NMR}\left(\mathrm{CD}_{2} \mathrm{Cl}_{2}, 128 \mathrm{MHz}\right)$ : $\delta 55.8$ (s, br). HRMS (EI, $m / z)$ : for $\mathrm{BC}_{6} \mathrm{Cl}_{5} \mathrm{Br}_{2}$ Calcd: 415.6902 . Found: 415.6912. IR (Nujol, $\mathrm{cm}^{-1}$ ): 1700 (w), 1653 (w), 1539 (s), 1457 (s), $1377(\mathrm{w}), 1338$ (s), 1303 (s), 1235 (s), 1132 (s), $976(\mathrm{~s}), 920(\mathrm{w}), 888$ (s), 861 (s), 814 (s), 715 (s). Anal. Calcd. for $\mathrm{BC}_{6} \mathrm{Cl}_{5} \mathrm{Br}_{2}$ : C 17.16 . Found: $\mathrm{C} 17.23$.

$\mathrm{B}\left(\mathrm{C}_{6} \mathrm{Cl}_{5}\right)\left(\mathrm{C}_{6} \mathrm{~F}_{5}\right)_{2}$ (3). Toluene $(150 \mathrm{~mL})$ was added to a stirred mixture of $\mathrm{B}\left(\mathrm{C}_{6} \mathrm{Cl}_{5}\right) \mathrm{Br}_{2}(6.78 \mathrm{~g}, 16.1 \mathrm{mmol})$ and $\mathrm{CuC}_{6} \mathrm{~F}_{5}(7.61 \mathrm{~g}, 33.0$ $\mathrm{mmol})$, followed by heating to $60^{\circ} \mathrm{C}$ for $4 \mathrm{~h}$. The initially translucent solution rapidly became cloudy, producing a white precipitate of $\mathrm{CuBr}$. Upon cooling, the solution was filtered through Celite and the residue washed with toluene $(2 \times 50 \mathrm{~mL})$, before removing the solvent under vacuum. The resultant off-white solid was then sublimed $\left(125^{\circ} \mathrm{C}, 0.01\right.$ mbar) to produce analytically pure $\mathrm{B}\left(\mathrm{C}_{6} \mathrm{Cl}_{5}\right)\left(\mathrm{C}_{6} \mathrm{~F}_{5}\right)_{2}$ (3) as a white powder $(7.80 \mathrm{~g}, 81 \%, 13.1 \mathrm{mmol})$. Crystals suitable for $\mathrm{X}$-ray diffraction were grown from slow-cooling of a toluene solution to $-30{ }^{\circ} \mathrm{C} .{ }^{13} \mathrm{C}\left\{{ }^{1} \mathrm{H}\right\}$ $\operatorname{NMR}\left(\mathrm{CD}_{2} \mathrm{Cl}_{2}, 75 \mathrm{MHz}\right): \delta 149.7\left(\mathrm{dm},{ }^{1} J_{\mathrm{CF}}=251 \mathrm{~Hz}\right.$, ortho- $\left.\mathrm{C}_{6} \mathrm{~F}_{5}\right) ; \delta$ $145.9\left(\mathrm{dm},{ }^{1} J_{\mathrm{CF}}=262 \mathrm{~Hz}\right.$, para- $\left.\mathrm{C}_{6} \mathrm{~F}_{5}\right) ; \delta 141.0\left(\mathrm{br}\right.$, ipso- $\left.\mathrm{C}_{6} \mathrm{Cl}_{5}\right) ; \delta 138.0$ $\left(\mathrm{dm},{ }^{1} J_{\mathrm{CF}}=249.5 \mathrm{~Hz}\right.$, meta- $\left.\mathrm{C}_{6} \mathrm{~F}_{5}\right) ; \delta 135.1\left(\mathrm{~s}\right.$, para- $\left.\mathrm{C}_{6} \mathrm{Cl}_{5}\right) ; \delta 132.3$, 131.3 (both s, meta- $\mathrm{C}_{6} \mathrm{Cl}_{5}$ and ortho- $\mathrm{C}_{6} \mathrm{Cl}_{5}$ ); $\delta 112.2\left(\mathrm{br}\right.$, ipso- $\left.\mathrm{C}_{6} \mathrm{~F}_{5}\right) .{ }^{11} \mathrm{~B}$ $\operatorname{NMR}\left(\mathrm{C}_{7} \mathrm{D}_{8}, 128 \mathrm{MHz}\right): 63.6(\mathrm{~s}, \mathrm{br}) .{ }^{19} \mathrm{~F}$ NMR $\left(\mathrm{C}_{7} \mathrm{D}_{8}, 282.2 \mathrm{MHz}\right): \delta$ $-127.3\left(\mathrm{~d}, 4 \mathrm{~F},{ }^{3} J_{\mathrm{FF}}=22 \mathrm{~Hz}\right.$, ortho- $\left.\mathrm{C}_{6} \mathrm{~F}_{5}\right), \delta-141.0\left(\mathrm{t}, 2 \mathrm{~F},{ }^{3} \mathrm{~J}_{\mathrm{FF}}=23 \mathrm{~Hz}\right.$, para- $\left.\mathrm{C}_{6} \mathrm{~F}_{5}\right), \delta-159.9\left(\mathrm{~m}, 4 \mathrm{~F}\right.$, meta- $\left.\mathrm{C}_{6} \mathrm{~F}_{5}\right)$. HRMS (EI, $\left.\mathrm{m} / z\right)$ : for $\mathrm{BC}_{18} \mathrm{C}_{15} \mathrm{~F}_{10}$ Calcd: 591.8378. Found: 591.8376. IR (Nujol, $\mathrm{cm}^{-1}$ ): $1700(\mathrm{~m}), 1653(\mathrm{~m}), 1646(\mathrm{~m}), 1559(\mathrm{~m}), 1549(\mathrm{~m}), 1521(\mathrm{~s}), 1507$ $(\mathrm{w}), 1482(\mathrm{~s}), 1437(\mathrm{~m}), 1382(\mathrm{~m}), 1336(\mathrm{~m}), 1322(\mathrm{~m}), 1235(\mathrm{w})$, $1167(\mathrm{~m}), 1142(\mathrm{w}), 1015(\mathrm{w}), 979(\mathrm{~s}), 674(\mathrm{~m}), 668(\mathrm{~m}), 659(\mathrm{w})$. Anal. Calcd. for $\mathrm{BC}_{18} \mathrm{C}_{15} \mathrm{~F}_{10}$ : C 36.38. Found: C 36.27.

$\mathrm{B}\left(\mathrm{C}_{6} \mathrm{Cl}_{5}\right)_{2} \mathrm{Cl}(4)$. Hexane $(100 \mathrm{~mL})$ was slowly added to a stirred solution of $\mathrm{C}_{6} \mathrm{Cl}_{5} \mathrm{Li}$ (from $29.0 \mathrm{mmol}$ of $\mathrm{C}_{6} \mathrm{Cl}_{6}$ ) at $-78{ }^{\circ} \mathrm{C}$, resulting in the formation of a precipitate. $\mathrm{BCl}_{3}(14 \mathrm{~mL}, 14.0 \mathrm{mmol}, 1.0 \mathrm{M}$ in heptane) was then syringed into this suspension and the reaction mixture allowed to slowly warm up to room temperature in the $\mathrm{CO}_{2(\mathrm{~s})}$ / acetone cooling bath, followed by further stirring for $12 \mathrm{~h}$. The solvent was then stripped under vacuum and the orange residue extracted with $\mathrm{CH}_{2} \mathrm{Cl}_{2}(2 \times 100 \mathrm{~mL})$ and filtered through Celite. The solution was then reduced to minimum volume and cooled to $-35^{\circ} \mathrm{C}$, affording an orange powder after washing with cold $\left(-35^{\circ} \mathrm{C}\right) \mathrm{CH}_{2} \mathrm{Cl}_{2}(20 \mathrm{~mL})$ and drying under vacuum. Two further crops were isolated from the mother liquor following the latter procedure. A final recrystallization from slowcooling a saturated $\mathrm{CH}_{2} \mathrm{Cl}_{2}$ solution to $-35^{\circ} \mathrm{C}$ gave pale orange needles of $\mathrm{B}\left(\mathrm{C}_{6} \mathrm{Cl}_{5}\right)_{2} \mathrm{Cl}$ (4), which were dried in vacuo $(4.09 \mathrm{~g}, 54 \%, 7.5 \mathrm{mmol})$. ${ }^{13} \mathrm{C}\left\{{ }^{1} \mathrm{H}\right\} \operatorname{NMR}\left(\mathrm{CD}_{2} \mathrm{Cl}_{2}, 75 \mathrm{MHz}\right): \delta 136.4$ (s, para- $\left.\mathrm{C}_{6} \mathrm{Cl}_{5}\right) ; \delta 134.7$, 133.1 (s, meta- $\mathrm{C}_{6} \mathrm{Cl}_{5}$ and ortho- $\mathrm{C}_{6} \mathrm{Cl}_{5}$ ). Resonance for ipso- $\mathrm{C}_{6} \mathrm{Cl}_{5}$ not observed. ${ }^{11} \mathrm{~B}$ NMR $\left(\mathrm{CD}_{2} \mathrm{Cl}_{2}, 128 \mathrm{MHz}\right): \delta 62.9$ (s, br). HRMS (EI, $m$ / $z)$ : for $\mathrm{BC}_{12} \mathrm{Cl}_{11}$ Calcd: 539.6667. Found: 539.6660. IR (Nujol, $\mathrm{cm}^{-1}$ ): $1700(\mathrm{~m}), 1684(\mathrm{~m}), 1653(\mathrm{~m}), 1559(\mathrm{w}), 1540(\mathrm{w}), 1521(\mathrm{w}), 1457(\mathrm{~s})$, 1377 (s), 1322 (s), 1298 (s), 668 (w). Anal. Calcd. for $\mathrm{BC}_{12} \mathrm{Cl}_{11}$ : C 26.45. Found: C 26.57 .

$\mathrm{B}\left(\mathrm{C}_{6} \mathrm{Cl}_{5}\right)_{2}\left(\mathrm{C}_{6} \mathrm{~F}_{5}\right)(5)$. A greaseless glass ampule was charged with a stirrer bar, $\mathrm{B}\left(\mathrm{C}_{6} \mathrm{Cl}_{5}\right)_{2} \mathrm{Cl}(4.09 \mathrm{~g}, 7.5 \mathrm{mmol}), \mathrm{CuC}_{6} \mathrm{~F}_{5}(1.82 \mathrm{~g}, 7.9 \mathrm{mmol})$ and toluene $(100 \mathrm{~mL})$. The vessel was sealed and heated to $80^{\circ} \mathrm{C}$ (temperatures above this result in decomposition of $\mathrm{CuC}_{6} \mathrm{~F}_{5}$ ) with stirring for $72 \mathrm{~h}$ before being cooled and the solvent removed in vacuo. The compound was extracted using $\mathrm{CH}_{2} \mathrm{Cl}_{2}(2 \times 50 \mathrm{~mL})$, followed by filtering through Celite and solvent removal in vacuo. The resultant residue was recrystallized from toluene/hexane $(1: 2)$ at $-78{ }^{\circ} \mathrm{C}$, producing a microcrystalline solid which was washed with cold $\left(-78{ }^{\circ} \mathrm{C}\right)$ pentane $(2 \times 20 \mathrm{~mL})$ and dried under vacuum to give spectroscopically pure 2 ( $3.39 \mathrm{~g}, 70 \%, 5.0 \mathrm{mmol})$. Crystals suitable for $\mathrm{X}$-ray diffraction were grown from slow evaporation of a saturated toluene solution. ${ }^{13} \mathrm{C}\left\{{ }^{1} \mathrm{H}\right\} \mathrm{NMR}\left(\mathrm{CD}_{2} \mathrm{Cl}_{2}, 75 \mathrm{MHz}\right): \delta 149.0\left(\mathrm{dm},{ }^{1} J_{\mathrm{CF}}=\right.$ $253 \mathrm{~Hz}$, ortho- $\left.\mathrm{C}_{6} \mathrm{~F}_{5}\right) ; \delta 145.9\left(\mathrm{dm},{ }^{1} J_{\mathrm{CF}}=261 \mathrm{~Hz}\right.$, para- $\left.\mathrm{C}_{6} \mathrm{~F}_{5}\right) ; \delta 138.0$ $\left(\mathrm{dm},{ }^{1} J_{\mathrm{CF}}=251 \mathrm{~Hz}\right.$, meta- $\left.\mathrm{C}_{6} \mathrm{~F}_{5}\right) ; \delta 139.6$ (br, ipso- $\left.\mathrm{C}_{6} \mathrm{Cl}_{5}\right) ; 136.6$ (s, para- $\mathrm{C}_{6} \mathrm{Cl}_{5}$ ); $\delta 133.0$ (s, meta- $\mathrm{C}_{6} \mathrm{Cl}_{5}$ and ortho- $\mathrm{C}_{6} \mathrm{Cl}_{5}$ ); $\delta 114.5$ (br, ipso- $\left.\mathrm{C}_{6} \mathrm{~F}_{5}\right) .{ }^{11} \mathrm{~B}$ NMR $\left(\mathrm{C}_{7} \mathrm{D}_{8}, 128 \mathrm{MHz}\right): 64.1$ (s, br). ${ }^{19} \mathrm{~F}$ NMR $\left(\mathrm{C}_{7} \mathrm{D}_{8}, 282.2 \mathrm{MHz}\right): \delta-127.2\left(\mathrm{~d}, 2 \mathrm{~F},{ }^{3} J_{\mathrm{FF}}=21 \mathrm{~Hz}\right.$, ortho- $\left.\mathrm{C}_{6} \mathrm{~F}_{5}\right), \delta$ $-141.4\left(\mathrm{t}, 1 \mathrm{~F},{ }^{3} J_{\mathrm{FF}}=21 \mathrm{~Hz}\right.$, para $\left.-\mathrm{C}_{6} \mathrm{~F}_{5}\right), \delta-159.7\left(\mathrm{~m}, 2 \mathrm{~F}\right.$, meta- $\left.\mathrm{C}_{6} \mathrm{~F}_{5}\right)$. 
HRMS (EI, $m / z$ ): for $\mathrm{BC}_{18} \mathrm{Cl}_{10} \mathrm{~F}_{5}$ Calcd: 675.6899. Found: 675.6774 . IR (Nujol, $\mathrm{cm}^{-1}$ ): 1700 (m), $1653(\mathrm{~m}), 1559(\mathrm{~m}), 1540(\mathrm{w}), 1521(\mathrm{~m})$, 1507 (w), 1481 (s), 1465 (s), 1394 (m), 1332 (s), 1313 (s), 1237 (m), $1190(\mathrm{w}), 1147(\mathrm{~m}), 1127(\mathrm{w}), 1104(\mathrm{w}), 973$ (s), $876(\mathrm{w}), 668(\mathrm{~m})$, $642(\mathrm{w})$. Anal. Calcd. for $\mathrm{BC}_{18} \mathrm{Cl}_{10} \mathrm{~F}_{5}$ : C 31.96. Found: C 32.27.

$\mathrm{B}\left(\mathrm{C}_{6} \mathrm{Cl}_{5}\right)_{3}(6)$. Hexane $\left(100 \mathrm{~mL}\right.$ ) was added to $\mathrm{C}_{6} \mathrm{Cl}_{5} \mathrm{Li}$ (from 31.2 mmol of $\mathrm{C}_{6} \mathrm{Cl}_{6}$ ), as detailed in the synthesis of 4 . To this slurry was added $\mathrm{BCl}_{3}(10 \mathrm{~mL}, 10 \mathrm{mmol}, 1.0 \mathrm{M}$ in heptane $)$ via syringe at $-78^{\circ} \mathrm{C}$. The solution was allowed to warm slowly to $-10^{\circ} \mathrm{C}$ and stirred for an hour before the cloudy orange suspension was removed from the cooling bath, and reacted for a further $12 \mathrm{~h}$. After quenching the reaction by addition of $0.5 \mathrm{~mL} \mathrm{H}_{2} \mathrm{O}$, the solvent was removed in vacuo and subsequent workup performed in air. $\mathrm{CH}_{2} \mathrm{Cl}_{2}(150 \mathrm{~mL})$ was used to extract the crude product, the slurry being filtered through Celite and the filter pad washed with further $\mathrm{CH}_{2} \mathrm{Cl}_{2}(2 \times 50 \mathrm{~mL})$. Solvent was removed using rotary evaporation, yielding an amber solid. Recrystallization using a minimum quantity of toluene at $100^{\circ} \mathrm{C}$ followed by rapid filtration through glass wool and slow cooling to room temperature led to the formation of pale yellow crystals of $\mathbf{3}$ (toluene). The toluene supernatant was siphoned off and the crystals washed with pentane $(2 \times$ $40 \mathrm{~mL})$, followed by drying overnight under vacuum $\left(1 \times 10^{-3} \mathrm{mbar}\right)$ to remove toluene of crystallization. Yield $3.26 \mathrm{~g}$ (42\%, $4.3 \mathrm{mmol})$. X-ray quality crystals were produced by a second toluene recrystallization.

${ }^{13} \mathrm{C}\left\{{ }^{1} \mathrm{H}\right\}$ NMR $\left(\mathrm{CD}_{2} \mathrm{Cl}_{2}, 75 \mathrm{MHz}\right): \delta 140.6$ (br, ipso- $\left.\mathrm{C}_{6} \mathrm{Cl}_{5}\right) ; 136.7$ (s, para- $\mathrm{C}_{6} \mathrm{Cl}_{5}$ ); $\delta 135.3,133.0$ (both s, meta- $\mathrm{C}_{6} \mathrm{Cl}_{5}$ and ortho- $\mathrm{C}_{6} \mathrm{Cl}_{5}$ ). ${ }^{11} \mathrm{~B}$ NMR $\left(\mathrm{C}_{7} \mathrm{D}_{8}, 128 \mathrm{MHz}\right)$ : $65.6(\mathrm{~s}, \mathrm{br})$. HRMS (EI, $\left.\mathrm{m} / \mathrm{z}\right)$ : for $\mathrm{BC}_{18} \mathrm{Cl}_{15}$ Calcd: 751.5421. Found: 751.5177. IR (Nujol, $\mathrm{cm}^{-1}$ ): 1700 (m), $1684(\mathrm{~m}), 1652(\mathrm{~m}), 1558(\mathrm{~m}), 1540(\mathrm{~m}), 1507(\mathrm{~m}), 1468(\mathrm{~s})$, 1334 (m), 1313 (m), 1232 (m), 1130 (w), 991 (w), 668 (m), $636(\mathrm{w})$. Anal. Calcd. for $\mathrm{BC}_{18} \mathrm{Cl}_{15}$ : C 28.49. Found: C 28.63.

\section{ASSOCIATED CONTENT}

Supporting Information. Table S1. Decomposition of the computed ${ }^{11} \mathrm{~B}$ isotropic shielding constants into diamagnetic and paramagnetic terms for $\mathrm{B}\left(\mathrm{C}_{6} \mathrm{~F}_{5}\right)_{3}, \mathrm{~B}\left(\mathrm{C}_{6} \mathrm{~F}_{5}\right)_{2}\left(\mathrm{C}_{6} \mathrm{Cl}_{5}\right)$ (3), $\mathrm{B}\left(\mathrm{C}_{6} \mathrm{~F}_{5}\right)\left(\mathrm{C}_{6} \mathrm{Cl}_{5}\right)_{2}(5)$, and $\mathrm{B}\left(\mathrm{C}_{6} \mathrm{Cl}_{5}\right)_{3}(6)$. CIF data for 3,5 and 6 , and complete ref 59 . This material is available free of charge via the Internet at http://pubs.acs.org.

\section{AUTHOR INFORMATION}

Corresponding Author

a.ashley@imperial.ac.uk; dermot.ohare@chem.ox.ac.uk

\section{Present Addresses}

${ }^{\ddagger}$ Department of Chemistry, Imperial College London, London SW7 2AZ

\section{ACKNOWLEDGMENT}

We thank Balliol College, Oxford for a Junior Research Fellowship to A.E.A. and the Royal Society for a University Research Fellowship to G.G.W. We also thank EPSRC and the University of Oxford Challenge Seed Fund for financial support and Dr Jeffrey Harmer (CAESR, University of Oxford) for assistance with the EPR spectroscopy.

\section{REFERENCES}

(1) (a) Massey, A. G.; Park, A. J.; Stone, F. G. A. Proc. Chem. Soc., London 1963, 212. (b) Massey, A. G.; Park, A. J. J. Organomet. Chem. 1964, 2, 245-250. (c) Massey, A. G.; Park, A. J. J. Organomet. Chem. $1966,5,218-225$.
(2) (a) Gevorgyan, V.; Rubin, M.; Benson, S.; Liu, J. X.; Yamamoto, Y. J. Org. Chem. 2000, 65, 6179-6186. (b) Blackwell, J. M.; Sonmor, E. R.; Scoccitti, T.; Piers, W. E. Org. Lett. 2000, 2, 3921-3923. (c) Parks, D. J.; Piers, W. E. J. Am. Chem. Soc. 1996, 118, 9440-9441. (d) Morrison, D. J.; Piers, W. E. Org. Lett. 2003, 5, 2857-2860. (e) Blackwell, J. M.; Foster, K. L.; Beck, V. H.; Piers, W. E. J. Org. Chem. 1999, 64, 4887-4892. (f) Morrison, D. J.; Blackwell, J. M.; Piers, W. E. Pure Appl. Chem. 2004, 76, 615-623.

(3) (a) Krossing, I.; Raabe, I. Angew. Chem., Int. Ed. 2004, 43, 2066-2090. (b) Bochmann, M.; Lancaster, S. J.; Hannant, M. D.; Rodriguez, A.; Schormann, M.; Walker, D. A.; Woodman, T. J. Pure Appl. Chem. 2003, 75, 1183-1195. (c) Lancaster, S. J.; Walker, D. A.; Thornton-Pett, M.; Bochmann, M. Chem. Commun. 1999, 1533-1534. (d) Lancaster, S. J.; Rodriguez, A.; Lara-Sanchez, A.; Hannant, M. D.; Walker, D. A.; Hughes, D. H.; Bochmann, M. Organometallics 2002, 21, 451-453. (e) LaPointe, R. E.; Roof, G. R.; Abboud, K. A.; Klosin, J. J. Am. Chem. Soc. 2000, 122, 9560-9561. (f) Yang, X. M.; Stern, C. L.; Marks, T. J. J. Am. Chem. Soc. 1994, 116, 10015-10031. (g) Bernsdorf, A.; Brand, H.; Hellmann, R.; Kockerling, M.; Schulz, A.; Villinger, A.; Voss, K. J. Am. Chem. Soc. 2009, 131, 8958-8970. (h) Chen, E. Y. X.; Marks, T. J. Chem. Rev. 2000, 100, 1391-1434.

(4) (a) Beckett, M. A.; Brassington, D. S.; Coles, S. J.; Hursthouse, M. B. Inorg. Chem. Commun. 2000, 3, 530-533. (b) Jacobsen, H.; Berke, H.; Doring, S.; Kehr, G.; Erker, G.; Frohlich, R.; Meyer, O. Organometallics 1999, 18, 1724-1735.

(5) (a) Erker, G. Dalton Trans. 2005, 1883-1890. (b) Piers, W. E.; Chivers, T. Chem. Soc. Rev. 1997, 26, 345-354.

(6) (a) Stephan, D. W. Dalton Trans. 2009, 3129-3136. (b) Kenward, A. L.; Piers, W. E. Angew. Chem., Int. Ed. 2008, 47, 38-41. (c) Stephan, D. W.; Erker, G. Angew. Chem., Int. Ed. 2010, 49, 46-76.

(7) (a) Dureen, M. A.; Stephan, D. W. J. Am. Chem. Soc. 2009, 131, 8396-8397. (b) Chen, C.; Eweiner, F.; Wibbeling, B.; Froehlich, R.; Senda, S.; Ohki, Y.; Tatsumi, K.; Grimme, S.; Kehr, G.; Erker, G. Chem. -Asian J. 2010, 5, 2199-2208. (c) Chen, C.; Froehlich, R.; Kehr, G.; Erker, G. Chem. Commun. 2010, 46, 3580-3582. (d) Dureen, M. A.; Brown, C. C.; Stephan, D. W. Organometallics 2010, 29, 6422-6432. (e) Dureen, M. A.; Brown, C. C.; Stephan, D. W. Organometallics 2010, 29, 6594-6607. (f) Jiang, C.; Blacque, O.; Berke, H. Organometallics 2010, 29, 125-133. (g) Moemming, C. M.; Froemel, S.; Kehr, G.; Froehlich, R.; Grimme, S.; Erker, G. J. Am. Chem. Soc. 2009, 131, 12280-12289. (h) Sortais, J.-B.; Voss, T.; Kehr, G.; Froehlich, R.; Erker, G. Chem. Commun. 2009, 7417-7418. (i) Voss, T.; Chen, C.; Kehr, G.; Nauha, E.; Erker, G.; Stephan, D. W. Chem.-Eur. J. 2010, 16, 3005-3008.

(8) (a) Momming, C. M.; Otten, E.; Kehr, G.; Frohlich, R.; Grimme, S.; Stephan, D. W.; Erker, G. Angew. Chem., Int. Ed. 2009, 48, 66436646. (b) Zhao, X.; Stephan, D. W. Chem. Commun. 2011, 47, 18331835. (c) Appelt, C.; Westenberg, H.; Bertini, F.; Ehlers, A. W.; Slootweg, J. C.; Lammertsma, K.; Uhl, W. Angew. Chem., Int. Ed. 2011, 50, 3925-3928. (d) Tran, S. D.; Tronic, T. A.; Kaminsky, W.; Heinekey, D. M.; Mayer, J. M. Inorg. Chim. Acta 2011, 369, 126-132.

(9) (a) Neu, R. C.; Otten, E.; Lough, A.; Stephan, D. W. Chem. Sci. 2011, 2, 170-176. (b) Otten, E.; Neu, R. C.; Stephan, D. W. J. Am. Chem. Soc. 2009, 131, 9918-9919.

(10) (a) Ashley, A. E.; Thompson, A. L.; O'Hare, D. Angew. Chem., Int. Ed. 2009, 48, 9839-9843. (b) Menard, G.; Stephan, D. W. J. Am. Chem. Soc. 2010, 132, 1796-1797.

(11) (a) Spies, P.; Schwendemann, S.; Lange, S.; Kehr, G.; Froehlich, R.; Erker, G. Angew. Chem., Int. Ed. 2008, 47, 7543-7546. (b) Chase, P. A.; Jurca, T.; Stephan, D. W. Chem. Commun. 2008, 1701-1703.

(12) Beckett, M. A.; Strickland, G. C.; Holland, J. R.; Varma, K. S. Polymer 1996, 37, 4629-4631.

(13) Eros, G.; Mehdi, H.; Papai, I.; Rokob, T. A.; Kiraly, P.; Tarkanyi, G.; Soos, T. Angew. Chem., Int. Ed. 2010, 49, 6559-6563.

(14) Piers, W. E.; Irvine, G. J.; Williams, V. C. Eur. J. Inorg. Chem. 2000, 2131-2142.

(15) McDaniel, D. S.; Brown, H. C. J. Org. Chem. 1958, 23, 420-427.

(16) Christoph Elschenbroich, A. S. Organometallics: A Concise Introduction, 2nd ed.; Wiley VCH: Weinheim, 1992. 
(17) (a) Niedenzu, K. Organomet. Chem. Rev. 1966, 1, 305-329. (b) Parks, D. J.; Piers, W. E.; Yap, G. P. A. Organometallics 1998, 17, 5492-5503. (c) Sundararaman, A.; Jakle, F. J. Organomet. Chem. 2003, 681, 134-142.

(18) Rausch, M. D.; Tibbetts, F. E.; Gordon, H. B. J. Organomet. Chem. 1966, 5, 493.

(19) Welch, G. C.; Juan, R. R. S.; Masuda, J. D.; Stephan, D. W. Science 2006, 314, 1124-1126.

(20) Chivers, T.; David, B. J. Organomet. Chem. 1968, 13, 177-186.

(21) Williams, V. C.; Piers, W. E.; Clegg, W.; Elsegood, M. R. J.; Collins, S.; Marder, T. B. J. Am. Chem. Soc. 1999, 121, 3244-3245.

(22) Confirmation of the formation of a four coordinate complex is revealed by measuring $\Delta \delta_{\mathrm{m}, \mathrm{p}}$, the difference of the chemical shifts between the para-F and meta-F resonances, which decrease from 18.9 $\mathrm{ppm}$ to ca. $9 \mathrm{ppm}$ upon rehybridization from a 3- to 4-coordinate complex.

(23) Horton, A. D.; deWith, J. Organometallics 1997, 16, 5424-5436.

(24) Crystals of 3 had to be manipulated at temperatures below $0{ }^{\circ} \mathrm{C}$ to inhibit dissolution in either Paratone or perfluoropolyether oil.

(25) For consistency, the right-handed propeller is shown in all crystallographic figures.

(26) A common test for planarity is to sum-all-angles around a central atom and comparing with the ideal $360^{\circ}$; in this case however the sum of the angles about $\mathrm{B}$ is $360^{\circ}$. However, this test this can be extremely insensitive to planarity and the reader is directed to ref 27 for examples. Using the method applied in the text, the largest deviation is seen for $\mathbf{5}(0.0028 \AA$ ) , confirming a planar assignment for 3, 5 and $\mathbf{6}$.

(27) Blake, A. J.; Cole, J. M.; Evans, J. S. O.; Main, P.; Parsons, S.; Watkin, D. J. Crystal Structure Analysis: Principles and Practice, 2nd ed.; Oxford University Press: Oxford, 2009.

(28) Tulinsky, A.; White, J. G. Acta Crystallogr. 1958, 11, 7-14.

(29) Power, P. P.; Olmstead, M. M. J. Am. Chem. Soc. 1986, $108,4253-4236$.

(30) Zettler, F.; Hausen, H. D.; Hess, H. J. Organomet. Chem. 1974, $72,157-162$.

(31) Massey, A. G.; Park, A. J. J. Organomet. Chem. 1966, 5, 218-225.

(32) (a) Danopoulos, A. A.; Galsworthy, J. R.; Green, M. L. H.; Cafferkey, S.; Doerrer, L. H.; Hursthouse, M. B. Chem. Commun. 1998, 2529-2530. (b) Doerrer, L. H.; Green, M. L. H. J. Chem. Soc., Dalton Trans. 1999, 4325-4329. (c) Beringhelli, T.; Maggioni, D.; D’Alfonso, G. Organometallics 2001, 20, 4927-4938.

(33) Timoshkin, A. Y.; Frenking, G. Organometallics 2008, 27, 371-380.

(34) Bergquist, C.; Bridgewater, B. M.; Harlan, C. J.; Norton, J. R.; Friesner, R. A.; Parkin, G. J. Am. Chem. Soc. 2000, 122, 10581-10590.

(35) Bergquist, C.; Parkin, G. J. Am. Chem. Soc. 1999, 121, $6322-6323$.

(36) (a) Childs, R. F.; Mulholland, D. L.; Nixon, A. Can. J. Chem. 1982, 60, 801-808. (b) Lappert, M. F. J. Chem Soc. 1961, 817. (c) Lappert, M. F. J. Chem Soc. 1962, 542. (d) Mayer, U.; Gutmann, V.; Gerger, W. Monatsh. Chem. 1975, 106, 1235-1257. (e) Gutmann, V. Coord. Chem. Rev. 1976, 18, 225-255.

(37) (a) Welch, G. C.; Cabrera, L.; Chase, P. A.; Hollink, E.; Masuda, J. D.; Wei, P. R.; Stephan, D. W. Dalton Trans. 2007, 3407-3414. (b) Beckett, M. A.; Strickland, G. C.; Holland, J. R.; Varma, K. S. Polymer 1996, 37, 4629-4631.

(38) Britovsek, G. J. P.; Ugolotti, J.; White, A. J. P. Organometallics 2005, 24, 1685-1691.

(39) Pearson, R. G. J. Am. Chem. Soc. 1963, 85, 3533-\&.

(40) Mackle, H.; Sutton, L. E. Trans. Faraday Soc. 1951, 47, 691-699.

(41) Bandoli, G.; Bortoloz., G; Clemente, D. A.; Croatto, U.; Panatton., C J. Chem. Soc. A 1970, 2778-\&.

(42) Harlan, C. J.; Hascall, T.; Fujita, E.; Norton, J. R. J. Am. Chem. Soc. 1999, 121, 7274-7275.

(43) Cummings, S. A.; Iimura, M.; Harlan, C. J.; Kwaan, R. J.; Trieu, I. V.; Norton, J. R.; Bridgewater, B. M.; Jakle, F.; Sundararaman, A.; Tilset, M. Organometallics 2006, 25, 1565-1568.
(44) Compton, R. G.; Banks, C. E. Understanding Voltammetry; World Scientific Publishing: Singapore, 2007.

(45) Testa, A. C.; Reinmuth, W.H. Anal. Chem. 1961, 33, 1320-1324.

(46) (a) Ballester, M.; Riera-Figueras, J.; Castaner, J.; Badfa, C.; Monso, J. M. J. Am. Chem. Soc. 1971, 93, 2215-2225. (b) Ballester, M. Acc. Chem. Res. 1985, 18, 380-387.

(47) Chivers, T.; Schatte, G. Eur. J. Inorg. Chem. 2003, 3314-3317.

(48) Strauss, S. H. Chem. Rev. 1993, 93, 927-942.

(49) Frohn, H. J.; Jakobs, S. J. Chem. Soc., Chem. Commun. $1989,625-627$.

(50) Gritzner, G.; Kuta, J. Pure Appl. Chem. 1984, 56, 461.

(51) Kwaan, R. J.; Harlan, C. J.; Norton, J. R. Organometallics 2001, 20, 3818-3820.

(52) Cairncross, A.; Sheppard, W. A.; Wonchoba, E. Org. Synth. 1988, 50-9, 875-882.

(53) Cosier, J.; Glazer, A. M. J. Appl. Crystallogr. 1986, 19, 105-107.

(54) Otwinowski, Z. ;Minor, W Processing of X-ray Diffraction Data Collected in Oscillation Mode In Methods in Enzymology; Carter, C. W., Sweet, R. M., Eds.; Academic Press: New York, 1997; p 276.

(55) Altomare, A.; Cascarano, G.; Giacovazzo, C.; Guagliardi, A.; Burla, M. C.; Polidori, G.; Camalli, M. J. Appl. Crystallogr. 1994, 27, 435.

(56) Betteridge, P. W.; Carruthers, J. R.; Cooper, R. I.; Prout, K.; Watkin, D. J. J. Appl. Crystallogr. 2003, 36, 1487. Cooper, R. I.; Thompson, A. L.; Watkin, D. J. J. Appl. Crystallogr. 2010, 43, 1100-1107.

(57) (a) Becke, A. D. J. Chem. Phys. 1993, 98, 5648-5652. (b) Lee, C.; Yang, W.; Parr, R. G. Phys. Rev. B 1988, 37, 785-789. (c) Vosko, S. H.; Wilk, L.; Nusair, M. Can. J. Phys. 1980, 58, 1200-1211. (d) Stephens, P. J.; Devlin, F. J.; Chabalowski, C. F.; Frisch, M. J. J. Phys. Chem. 1994, 98, 11623-11627.

(58) Schäfer, A.; Huber, C.; Ahlrichs, R. J. Chem. Phys. 1994, 100, $5829-5835$.

(59) Frisch, M. J. et al. Gaussian 03, Revision E.01; Gaussian, Inc.: Wallingford CT, 2003.

(60) (a) Ditchfield, R. Mol. Phys. 1974, 27, 789-807. (b) Wolinski, K.; Hinton, J. F.; Pulay, P. J. J. Am. Chem. Soc. 1990, 112, 8251-8260.

(61) Tomasi, J.; Mennucci, B.; Cammi, R. Chem. Rev. 2005, 105, 2999-3093.

(62) Jensen, F. J. Chem. Theory Comput. 2008, 4, 719-727. 